\title{
LATENT HEAT OF VAPORIZATION OF AMMONIA
}

\author{
By Nathan S. Osborne and Milton S. Van Dusen
}

\section{CONTENTS}

II. Previous determinations............................ 440

III. General description of apparatus and method $\ldots \ldots \ldots \ldots \ldots \ldots \ldots \ldots, 44^{2}$

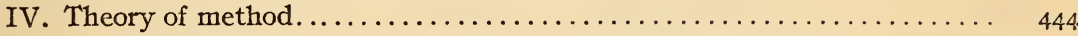

I. Notation...................................... 444

2. Determination of heat added........................ 446

3. Determination of latent heat of vaporization............. 446

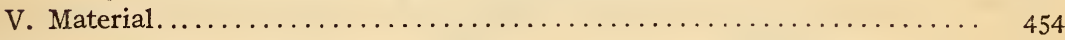

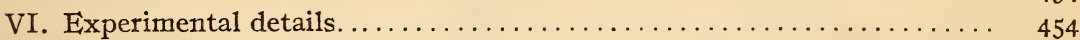

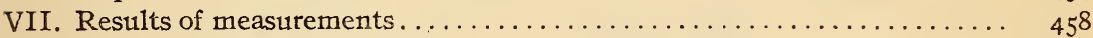

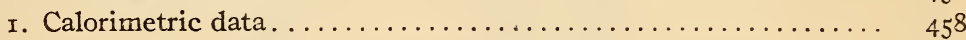

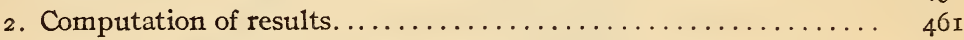

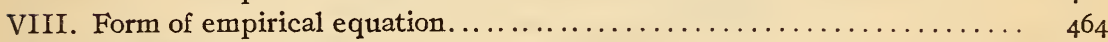

IX. Discussion of results . . . . . . . . .

X. Summary ......................................... 467

Appendixes:

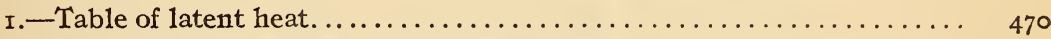

2.- Specific heat of saturated ammonia vapor................ $47 \mathrm{I}$

3.-Comparison of previous tables of latent heat of vaporization of ammonia. 472

\section{INTRODUCTION}

In tables of heat content of ammonia, such as engineers require, the latent heat of vaporization constitutes the major part. Nevertheless, the direct measurements of this property are among the rarest of the available experimental data. This is attributable probably to the fact that the latent heat of vaporization may, by thermodynamic formulas, be computed from other properties, more easily measurable; however, the data which have heretofore been available for this calculation have not been of a precision such as to yield satisfactory values for the latent heat. The measurements here presented have been carried out in response to the requests of the associations of refrigerating engineers in this 
country for more accurate data upon which to base calculations for machinery using ammonia in the production of artificial refrigeration.

\section{PREVIOUS DETERMINATIONS}

Results of previous determinations of the latent heat of vaporization of ammonia are represented graphically in Fig. I. The three curves also shown in this figure represent values computed from other data by Keyes, ${ }^{1}$ Goodenough and Mosher, ${ }^{2}$ and Holst ${ }^{3}$.

Regnault ${ }^{4}$ published a record of $\mathrm{I} 2$ experiments saved from

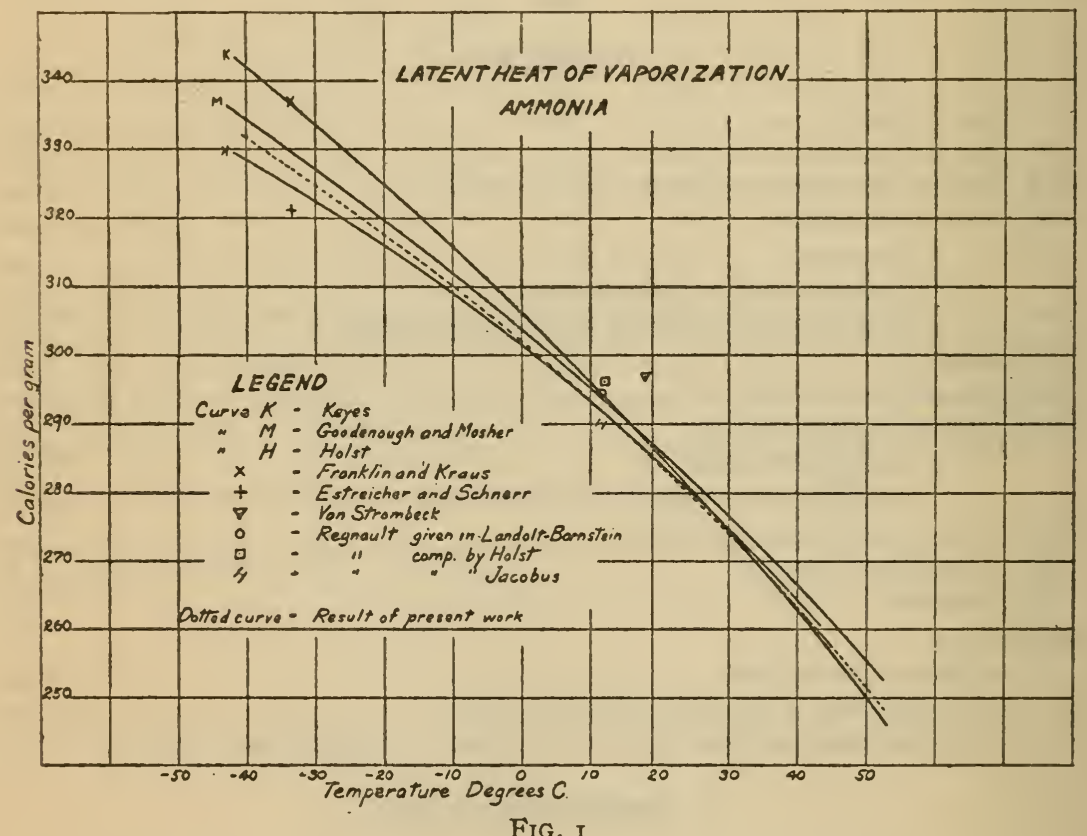

the ruins of his laboratory, destroyed during the siege of Paris in I870. The apparatus consisted of two calorimeters, the first, or evaporation calorimeter, in which the ammonia was allowed to evaporate from a steel container and flow through a chamber containing baffle plates, and the second, or expansion calorimeter, in which the ammonia vapor from the first calorimeter was allowed to expand to atmospheric pressure. The capacity of the liquid ammonia container in the first calorimeter was $246 \mathrm{~cm}^{3}$; but it was filled with various amounts, ranging from 17 to 134 grams in

\footnotetext{
1 Thermodynamic Properties of Ammonia. John Wiley Sons; rgr6.

2 Univ. of Ill., Bull. 66; rg13.

${ }^{3}$ Bull., Association Internationale du Froid, 51; rgr5.

- Ann. Chim. Phys., 24, p. 375; 1871.
} 
different experiments. In each experiment the ammonia was completely evaporated and all vapor expanded to atmospheric pressure. The observed fall in temperature of the water in the first calorimeter varied from $I^{\circ} .7$ to $13^{\circ}$, and in the second it was usually less than $r^{\circ}$. From the data obtained in the first calorimeter Regnault calculated a quantity $\lambda$, which is the heat required to change $I \mathrm{~g}$. of saturated liquid ammonia at the initial temperature and pressure to vapor at the mean temperature of the experiment and at a pressure equal to the pressure in the expansion chamber of the first calorimeter. He stated, however, that it is better to combine the results of the two calorimeters and so proceeded to calculate another quantity, $\lambda^{\prime}$, which is the heat required to change $I \mathrm{~g}$. of saturated liquid ammonia at the mean temperature and pressure to vapor at the mean temperature and at. atmospheric pressure.

Regnault's results have been variously interpreted by different writers. Holst computed the latent heat of vaporization from the observation in the first calorimeter and ignored the partial expansion below saturation pressure which occurred there. As a mean result he obtained 296 calories per gram at $12^{\circ} \mathrm{C}$. Jacobus ${ }^{5}$ computed the latent heat of vaporization from the observations in both calorimeters and obtained as a mean value 290 calories per gram at $\mathrm{I} 2^{\circ} \mathrm{C}$. Landolt and Börnstein ${ }^{6}$ give values from Regnault's data, the mean value at $12^{\circ}$ being 294.5 calories per gram.

Von Strombeck ${ }^{7}$ used the same type of apparatus as Regnault and obtained from $\mathrm{I} 2$ experiments a mean value of 296.5 calories per gram at $18^{\circ}$.

Estreicher and Schnerr ${ }^{8}$ (original paper unobtainable), according to Landolt and Börnstein, determined the heat of vaporation at the normal boiling point and obtained a value of 321 calories per gram at $-33^{\circ} .4 \mathrm{C}$.

Franklin and Kraus $^{9}$ determined the heat of vaporization at the normal boiling point. The apparatus consisted of a Dewar flask containing a liquid bath and a glass evaporating cell, each supplied with a platinum heating coil. The energy required to evaporate a certain volume of liquid ammonia was measured and the mass computed from the volume evaporated, using the value

\footnotetext{
5 Trans. A. S. M. E., 12, p. 307; 1890.

${ }^{6}$ Phys. Chem. Tabellen, Ed.; r9r2.

${ }^{7}$ Jour. Franklin Inst., 131, p. 470; 1891.

${ }^{8}$ Bull. de l'Ac. de Cracovie, p. 345; rgro (Phys. Chem. Tables; r9r2).

Jour. Phys. Chem., 11, p. 553; 1907.
} 
$0.67+$ for the density. The mean result from three experiments was 341 calories per gram. Recomputed, using more recent data for the density (0.683), the mean value becomes 337 calories per gram. This result is the same as that deduced by Franklin and Kraus from the absolute boiling point and the molecular elevation by Vań't Hoff's formula.

\section{GENERAL DESCRIPTION OF APPARATUS AND METHOD}

The calorimeter used in making the experimental determinations having been previously described in cletail, only a brief description is here given. ${ }^{10}$ The instrument is of the aneroid type, and was specially designed to meet the requirements of this investigation. A metal shell of sufficient strength is made in the form of a cylinder having a reentrant central tube. The interior annular space contains the material which is the subject of measurement; that is, ammonia, in the present case. An electric heating coil and resistance thermometer are located in the central tube. Heat developed in the coil is transmitted to the surrounding ammonia, the distribution being favored by radial metal vanes. A system of baffle plates in the top of the calorimeter is provided for drying the vapor during its removal in evaporation experiments. The interior surfaces of this calorimeter are tinned and the outside nickeled. The calorimeter is suspended within a thermally-controlled jacket, with an air space between for insulation. For evaluating the thermal leakage, thermocouples with multiple junctions distributed on the surfaces indicate temperature differences between calorimeter and jacket. This leakage can risually be annulled by the method of operation, which consists in keeping the average jacket and calorimeter surface temperatures equal.

In carrying out the experimental work, the heat supplied to the calorimeter for producing evaporation was developed at a nearly constant rate in the heating coil, using current furnished by storage battery. The temperature of calorimeter and contents, when in equilibrium, was measured by the resistance thermometer in the calorimeter. The energy supplied was determined by potentiometer measurements of current and potential drop and by the duration of the heating current as measured by the standard clock.

The sample of ammonia was introduced through one of the two tubes leading into the top of the calorimeter. The material was 
held in a steel reservoir which, after bəing weighed, was connected to this tube. The reservoir was immersed in a thermoregulated bath and served either as evaporator or condenser. Transfer occurred by distillation. The amount transferred to or from the calorimeter was determined by reweighing the reservoir and taking the difference. The method employea in the determinations of heat of vaporization was to evaporate, slichtly superheat, and withdraw from the calorimeter a measured amount of the ammonia. The approximate amount of heat required to effect this change was added and measured electrically, the small balance being due to the thermal leakage and the resulting change in temperature of the remaining ammonia, both of which were kept relatively small and were measured. The jacket was kept at a constant temperature during the experiment. The withdrawn vapor passed into the reservoir, where it was condensed. The rate of outflow of the vapor was governed by the difference between the vapor pressures in the calorimeter and condenser and by the throttling at the needle valve in the connecting tube outside the calorimeter. This valve was provided with a graduated circle and index for facilitating fine adjustment. The vapor pressure in the condenser was controlled approximately by regulating its temperature. The balance between heat added and heat extracted from the system could be maintained in two independent ways-either by control of the outflow, using the regulating valve, or by control of the heat added electrically.

The temperature of the vapor withdrawn was determined with reference to the initial temperature of the experiment by means of the thermocouples attached to the outflow tube, the common reference junction being on the jacket. Three junctions equidistant along the length of the tube are available for this observation.

The pressure within the calorimeter was indicated by means of a closed manometer, the connection to the interior being similar to that used for transfer of ammonia. This manometer might have been calibrated in terms of actual pressures; but it was found, instead, more convenient to calibrate and use it as a vaporpressure thermometer to indicate the temperature at the free surface of the liquid in the calorimeter, especially as the evaporation temperature - that is, the free surface temperature during evaporation-enters into the calculation. 


\section{THEORY OF METHOD}

In the preceding section an outline has been given of the arrangement of apparatus used and of the experimental procedure by which the calorimetric data are obtained for the determination of the latent heat of vaporization. Before passing on to the more complete details of the experiments and the results, the method of computation of the latent heat of vaporization from the observed data will be considered. A brief statement of the problem follows.

Initially, the system consisting of the calorimeter and the ammonia sample, is in thermal equilibrium, the contents comprising both liquid and vapor phases. A portion is withdrawn as superheated vapor with the addition of heat electrically and the remaining portion allowed to resume equilibrium; the aim being to adjust the rate of adding heat and the rate of evaporation so as to avoid large temperature changes throughout the process and to make the final temperature approximately equal to the initial.

The initial and final temperatures and amount removed are observed, and periodic observations made throughout the experiment of the following quantities:

I. Current in electric heating coil.

2. Potential drop in heating coil.

3. Temperature difference between calorimeter and jacket surfaces.

4. Vapor pressure in calorimeter.

5. Temperature of vapor as it leaves the calorimeter at the pressure existing therein.

Given these data and the necessary additional data from independent sources, the problem is to compute the latent heat of vaporization.

\section{NOTATION}

$V=$ volumetric capacity of calorimeter in cubic centimeters.

$N=$ heat capacity of calorimeter in joules per degree.

$Q=$ general symbol for heat added in joules.

$\Delta Q=$ heat added to contents of calorimeter during an experiment.

$M=$ mass in grams contained in calorimeter at any instant. $M_{1}, M_{2}=$ initial and final mass in calorimeter.

$\Delta M=$ mass, in grams, removed from calorimeter as superheated vapor. $\Delta M=M_{1}-M_{2}$.

$t=$ time 
$t^{\prime}=$ duration, in seconds, of a period of heating while the power, EI, is kept approximately constant.

$t_{2}=$ duration, in minutes, of entire experiment between observations of initial and final temperatures.

$I=$ calorimeter heating current in amperes.

$E=$ potential drop in volts across calorimeter heating coil.

$h=$ indication of integrating surface thermocouple in millimeters of galvanometer scale (mean value during experiment).

$B=$ coefficient of thermal leakage in joules per minute per millimeter galvanometer deflection.

$\theta=$ temperature in centigrade degrees of the thermodynamic scale.

$\theta_{1}=$ initial temperature of calorimeter and contents.

$\theta_{2}=$ final temperature of calorimeter and contents.

$p=$ pressure.

$\pi=$ saturation pressure.

$\pi_{\mathrm{e}}=$ instantaneous pressure in calorimeter.

$\theta_{\mathrm{e}}=$ instantaneous temperature of free surface in calorimeter (determined by $\pi_{\mathrm{e}}$ ).

$\theta_{\mathrm{s}}=$ instantaneous temperature of superheated vapor as it leaves the calorimeter.

$v=$ specific volume in cubic centimeters per gram of liquid. $v^{\prime}=$ specific volume in cubic centimeters per gram of vapor. $u=$ specific volume in cubic centimeters per gram of saturated liquid (i. e., when in equilibrium with saturated vapor).

$u^{\prime}=$ specific volume in cubic centimeters per gram of saturated vapor.

$\sigma=$ specific heat in joules per gram per degree of the saturated liquid.

$\sigma^{\prime}=$ specific heat in joules per gram per degree of the saturated vapor.

$L=$ latent heat of vaporization at temperature $\theta$ in joules per gram, defined as the heat required to change I gram of saturated liquid to saturated vapor at a constant temperature and pressure.

$x=$ mass of vapor in grams per gram total contents, i. e., dryness factor. 


\section{DETERMUNATION OF HEAT ADDED}

The heat supplied to the system composed of the calorimeter and the sample of ammonia which is the su'ject of measurement, consists of two parts, namely, the heat developed in the electric heating coil and the heat transferred by thermal leakage, of which the latter is usually zero or small in amount The heat thus supplied is distributed in two parts, namely, that which is absorbed by the calorimeter and that absorbed $t y$ the contents. Denoting by $\Delta Q$ the quantity of heat added to the ammonia in the calorimeter, the above statement is expressed by the equation

$$
\Delta Q=\int E I d_{t}^{2}+B t_{2} l_{2}-N\left(\theta_{2}-\theta_{1}\right)
$$

The coeificient of thermal leakage, $B$, and the heat capacity, $N$, of the calorimeter are obtained ft $\mathrm{m}$ the results of supplementary experiments described elsewhere, ${ }^{-2}$ being expressed as empirical functions of the temperature. Both $B$ and $N$ change so slowly with temperature that assuining for each a constant value corresponding to temperature $\frac{\theta_{1}+\theta_{2}}{2}$ for any experiment causes no appreciable error.

\section{DETERMINATION OF THE LATENT HEAT OF VAPORIZATION}

The process which goes on in the calorimeter can not be followed in detail, for during the period while heat is being added and vapor is being withdrawn the temperature is certainly not uniform, and furthermore, the temperature distribution in the ammonia is unknown. The observations during this period furnish merely knowledge at any instant of the temperature $\theta_{e}$ of the liquid surface at which the evaporation is occurring, and the temperature $\theta_{3}$ to which the vapor is superheated when withdrawn. It is thus evidently im ossible to analyze in detail the phenomena which actually occur and recourse must therefore be had to some other method of interpreting the observations quantitatively.

From the first law of thermodynamics it follows that when a mass of substance passes from a definite initial state to a definite final state the increase of internal energy-i. e., the excess of the heat supplied to the mass over the external work done by itdepends only on the two terminal states and is independent of the nature or the order of the intermediate processes. If in several different processes, each of which begins and ends in the same 
states, the mass of the substance does the same amount of external work, then the quantities of heat supplied to the mass are the same in each, regardless of the precise nature of the several processes.

To take advantage of this principle in the present instance, it is evidently necessary to assume an ideal process which would, if carried out, lead from the observed initial to the observed final state and involve the same amount of external work as the actual process, but which is so simple that the amount of heat required can be expressed in terms of known data and of the unknown latent heat of vaporization which is to be determined. If this expression be equated to the observed quantity of heat supplied during the actual experiment, the result is an equation from which the unknown latent heat $L$ may be found.

It will be simpler to consider first an ideal experiment in which it is supposed that $\theta_{\mathrm{e}}$ and $\theta_{\mathrm{s}}$ remain constant throughout the period, and after treating this case proceed to consider the effects of the small variations of $\theta_{\mathrm{e}}$ and $\theta_{\mathrm{s}}$ which occur in practice.

Of the several available ideal processes which lend themselves to the method of analysis outlined above, the one chosen by virtue of its physical simplicity consists of the following three consecutive steps:

(a) The $M_{1}$ grams of ammonia initially present in the calorimeter are changed in temperature from $\theta_{1}$ to $\theta_{\mathrm{e}}$, the volume remaining constant except for the negligible change in the volume of the calorimeter. This change of temperature is to be carried out so slowly that the liquid and the vapor remain sensibly in equilibrium under the vapor pressure corresponding to saturation at the instantaneous temperature.

(b) A mass $\Delta M$ grams is withdrawn as vapor. The necessary evaporation occurs at $\theta_{\mathrm{e}}$ so that the vapor comes out at the pressure $\pi_{\mathrm{e}}$ corresponding to $\theta_{\mathrm{e}}$; but before its exit the vapor is superheated to $\theta_{\mathrm{s}}$.

(c) The $M_{2}$ grams of ammonia remaining in the calorimeter are changed in temperature from $\theta_{\mathrm{\theta}}$ to $\theta_{2}$ by a process similar to $(a)$.

These three steps taken in succession constitute a process which starts and ends with the same states as in the ideal experiment. Furthermore, the external work done is the same, since the same mass of vapor is withdrawn under the same conditions of pressure and temperature, and the work due to changes of volume of the calorimeter is negligible. Hence, the quantity of heat supplied in an experiment made under the assumed restrictions as to the 
constancy of $\theta_{\mathrm{e}}$ and $\theta_{\mathrm{B}}$ is equal to the quantity that would have to be supplied if the ideal process were carried out as described. An expression for this quantity will be forthwith obtained.

During a change of temperature of a constant mass $M$ consisting of $M x$ grams of vapor and $M(I-x)$ grams of liquid, the whole being confined within a constant volume, the heat added is evidently expressed by the relation

$$
\frac{d Q}{d \theta}=M\left[(1-x) \sigma+x \sigma^{\prime}+L \frac{d x}{d \theta}\right]=M\left[\sigma+\left(\sigma^{\prime}-\sigma\right) x+L \frac{d x}{d \theta}\right]
$$

By means of the familiar general relation

$$
\sigma^{\prime}-\sigma=\frac{d L}{d \theta}-\frac{L}{\theta}=\theta \frac{d}{d \theta}\left(\frac{L}{\theta}\right)
$$

the elimination of $\sigma^{\prime}$ from (2) is accomplished and the resulting equation is expressed in the form

$$
\frac{d Q}{d \theta}=M\left[\sigma+\theta \frac{d}{d \theta}\left(x \frac{L}{\theta}\right)\right]
$$

To eliminate the factor $\frac{d}{d \theta}\left(x \frac{L}{\theta}\right)$, use is made of the relation

$$
x=\frac{1}{M} \frac{V-M u}{u^{\prime}-u}
$$

and of Clapeyron's general equation

$$
\frac{L}{\theta}=\left(u^{\prime}-u\right) \frac{d \pi}{d \theta}
$$

by multiplying (4) and (5) and differentiating

$$
\begin{aligned}
& \frac{d}{d \theta}\left(x \frac{L}{\theta}\right)=\frac{V}{M} \frac{d}{d \theta}\left(\frac{d \pi}{d \theta}\right)+\frac{d}{d \theta}\left(u \frac{d \pi}{d \theta}\right) \\
= & \frac{V}{M} \frac{d}{d \theta}\left(\frac{d \pi}{d \theta}\right)-\frac{\mathrm{I}}{\theta}\left[\frac{d}{d \theta}\left(\theta u \frac{d \pi}{d \theta}\right)-u \frac{d \pi}{d \theta}\right]
\end{aligned}
$$

By substitution into (3) from (6) and rearranging,

$$
\frac{d Q}{d \theta}=M\left[\sigma-\frac{d}{d \theta}\left(\theta u \frac{d \pi}{d \theta}\right)+u \frac{d \pi}{d \theta}\right]+V \theta \frac{d}{d \theta}\left(\frac{d \pi}{d \theta}\right)
$$


whence for a finite change of temperature $\theta_{\mathrm{I}}$ to $\theta_{\mathrm{II}}$

$$
Q_{\mathrm{I} \mathrm{II}}=M \int_{\mathrm{I}}^{\mathrm{II}}\left[\sigma-\frac{d}{d \theta}\left(\theta u \frac{d \pi}{d \theta}\right)+u \frac{d \pi}{d \theta}\right] d \theta+V \int_{\mathrm{I}}^{\mathrm{II}} \theta \frac{d}{d \theta}\left(\frac{d \pi}{d \theta}\right) d \theta
$$

By application of equation (8) to steps $(a)$ and (c) of the ideal process an expression for the quantity of heat added during the two steps is obtained, which after substitution of $M_{2}+\Delta M$ for $M_{1}$ and combination of integrals may be written

$$
\begin{aligned}
Q_{\mathrm{a}}+Q_{\mathrm{c}}=M_{2} \int_{\theta_{1}}^{\theta_{2}} & {\left[\sigma-\frac{d}{d \theta}\left(\theta u \frac{d \pi}{d \theta}\right)+u \frac{d \pi}{d \theta}\right] d \theta+V \int_{\theta_{1}}^{\theta_{2}} \theta \frac{d}{d \theta}\left(\frac{d \pi}{d \theta}\right) d \theta } \\
& +\Delta M \int_{\theta_{1}}^{\theta_{\mathrm{e}}}\left[\sigma-\frac{d}{d \theta}\left(\theta u \frac{d \pi}{d \theta}\right)+u \frac{d \pi}{d \theta}\right] d \theta
\end{aligned}
$$

Step (b) yet remains to be considered. During this step there is evaporated in addition to the $\Delta M$ grams withdrawn, the amount by which the mass of vapor within the calorimeter is increased. If the total mass of ammonia within the calorimeter is changed from $M_{1}$ to $M_{2}$, then by equation (4) this increase of vapor is

$$
\frac{V-M_{2} u_{\mathrm{e}}}{u_{e}^{\prime}-u_{\mathrm{e}}}-\frac{V-M_{1} u_{\mathrm{e}}}{u_{\mathrm{e}}^{\prime}-u_{\mathrm{e}}}=\Delta M \frac{u_{\mathrm{e}}}{u_{\mathrm{e}}^{\prime}-u_{\mathrm{e}}}
$$

The whole mass of ammonia evaporated can be written, using equation (5)

$$
\Delta M+\Delta M \frac{u_{\mathrm{e}}}{u_{\mathrm{e}}^{\prime}-u_{\mathrm{e}}}=\Delta M\left[\mathrm{I}+\left(\frac{\theta}{L} u \frac{d \pi}{d \theta}\right)_{\mathrm{e}}\right]
$$

and the heat required for this evaporation is $L_{e}$ times this mass. After the evaporation the mass $\Delta \mathrm{M}$ is superheated to $\theta_{\mathrm{s}}$, which requires the amount of heat

$$
\Delta M \int_{\theta_{\mathrm{e}}}^{\theta_{s}} C_{p}^{\prime} d \theta
$$

The whole quantity of heat which must be supplied during step (b) is therefore

$$
Q_{\mathrm{b}}=\Delta M\left[L_{\mathrm{e}}+\left(\theta u \frac{d \pi}{d \theta}\right)_{\mathrm{e}}+\int_{0_{\mathrm{o}}}^{\theta_{\mathrm{e}}} C^{\prime}{ }_{p} d \theta\right]
$$


The whole quantity of heat $Q_{\mathrm{abo}}$ supplied during the three steps of the process is obtained by adding equations (9) and (I 2). If $L_{1}+\int_{\theta_{1}}^{\theta_{e}} \frac{d L}{d \theta} d \theta$ be substituted for $L_{\theta}$, the resulting equation after cancellation and rearrangement may be written

$$
\begin{gathered}
Q_{\mathrm{abc}}=\Delta M L_{1}+\Delta M\left(\theta u^{\frac{d \pi}{d \theta}}\right)_{1}+\Delta M \int_{\theta_{1}}^{\theta_{\mathrm{e}}}\left(\sigma+\frac{d L}{d \theta}+u \frac{d \pi}{d \theta}\right) d \theta \\
+\Delta M \int_{\theta_{0}}^{\partial_{0}} C_{p}^{\prime} d \theta+M_{2} \int_{\theta_{1}}^{\theta_{2}}\left[\sigma+\frac{V}{M} \theta \frac{d}{d \theta}\left(\frac{d \pi}{d \bar{\theta}}\right)-\theta \frac{d}{d \theta}\left(u \frac{d \pi}{d \theta}\right)\right] d \theta
\end{gathered}
$$

In its present form equation (13) admits of verification from a slightly different point of view. By examination of the terms in the second member of this equation it may be shown that thus expressed the heat added to the ammonia corresponds to the heat which would be added in a different program of processes, likewise beginning and ending in the same terminal states and involving the same external work as the experimental case, but in which program the several changes affecting $\Delta M$, the amount removed, occur simultaneously, and independently of the change affecting $M_{2}$, the amount remaining behind. Taking the terms successively the amounts of heat expressed by the several terms may be identified with definite thermal processes, corresponding to the respective terms, as follows:

(I.) Heat required to evaporate the mass $\Delta M$ at $\theta_{1}$; (2) heat required to evaporate at $\theta_{1}$, the amount to replace with vapor the $\Delta M$ grams of liquid evaporated and removed; (3) heat required in the process of throttling from $\theta_{1} \pi_{1}$ to $\theta_{\mathrm{e}} \pi_{\mathrm{e}}$ the $\Delta M$ grams of vapor, kept saturated; $(4)$ heat required to superheat from $\theta_{\mathrm{e}}$ to $\theta_{\mathrm{s}}$ at pressure $\pi_{\mathrm{e}}$ the amount $\Delta M$ removed; (5) heat required to change from $\theta_{1}$ to $\theta_{2}$ under saturation conditions the amount $M_{2}$ remaining in the calorimeter. ${ }^{12}$

The first four terms, regardless of the precise manner in which the processes occur, are dependent upon the actual changes produced in the process of removing $\Delta M$ grams as vapor, and are independent of the last term, which depends upon the initial and final states of the material which remains in the calorimeter. Nothing physically impossible is implied in the simultaneous operation of these four processes, and supplemented by the process

12 The details of this analysis, which is perhaps more interesting than essential, may provide a useful problem for students in thermodynamics. 
corresponding to the fifth term, by which the remaining material is brought to the final state of equilibrium, the entire program involves the same changes in state and the expenditure of the same external work as an actual experiment carried out under the assumed ideal conditions. An alternative method of deducing equation (13) is provided by consideration of a process of this kinc which, although more complex, corresponds better to the actual process occurring in the calorimeter than the one first chosen.

The equation as developed above expresses the heat, $Q_{\mathrm{abc}}$, added when the entire amount, $\Delta M$, is evaporated at a constant temperature $\theta_{\mathrm{e}}$ and removed at the constant pressure $\pi_{\mathrm{e}}$ and constant temperature $\theta_{\mathrm{B}}$. In the actual experiments, however, the temperaiures of evaporation and superheat do vary somewhat during the process of evaporation and removal. It is therefore in -cessary to generalize equation ( 13 ) so as to take account of these variations. Obviously, only the terms which depend upon $\theta_{\theta}$ and $\theta_{\mathrm{s}}$ need be considered with respect to the change which is required in the equation.

For convenience let $Q^{\prime \prime \prime}$ denote the part of the heat added which depends on the temperature of evaporation and temperature of superheat. Then from equation (I3), since only the third and fourth terms depend on these two temperatures, it follows that

$$
Q^{\prime \prime \prime}=\Delta M\left[\int_{\theta_{1}}^{\theta_{\theta}}\left(\sigma+\frac{d L}{d \theta}+u \frac{d \pi}{d \theta}\right) d \theta+\int_{\theta_{\mathrm{e}}}^{\theta_{\mathrm{s}}} C^{\prime}{ }_{p} d \theta\right]
$$

The factor $\Delta M$ does not depend on the temperatures, $\theta_{\mathrm{e}}$ and $\theta_{\mathrm{B}}$ being determined arbitrarily by the operator; hence, by differentiating (16) with respect to $M$, the quantity of heat, $d Q^{\prime \prime \prime}$, added by virtue of the departure of these temperatures from the initial temperature $\theta_{1}$, while an amount, $d M$, is removed, is given by the equation:

$$
d Q^{\prime \prime \prime}=d M\left[\int_{\theta_{1}}^{\theta_{e}}\left(\sigma+\frac{d L}{d \theta}+u \frac{d \pi}{d \theta}\right) d \theta+\int_{\theta_{0}}^{\theta_{\theta}} C_{p}^{\prime} d \theta\right]
$$

The total amount, $Q^{\prime \prime}{ }^{\prime}$, for the entire mass $\Delta M$, is obtained by integrating ( 17 ) with respect to $M$, which gives the equation

$$
Q^{\prime \prime \prime}=\int_{0}^{\Delta M} d M\left[\int_{0}^{\theta_{\mathrm{e}}}\left(\sigma+\frac{d L}{d \theta}+u \frac{d \pi}{d \theta}\right) d \theta+\int_{\theta_{0}}^{\theta_{\mathrm{s}}} C^{\prime}{ }_{p} d \theta\right]
$$


in which $\theta_{\theta}$ and $\theta_{\mathbf{s}}$ are instantaneous values. Before this integration with respect to $M$ can be performed, the expression in the brackets must be expressed as a function of $M$ unless it can be evaluated as a constant. Now, if the data which are available for evaluation of the functions $\sigma+\frac{d L}{d \theta}+u \frac{d \pi}{d \theta}$ and $C_{p}^{\prime}$, within the temperature range of the present experiments, show that these functions change slowly enough with temperature, then for the small intervals of temperature, $\theta_{0}-\theta_{1}$ and $\theta_{8}-\theta_{\theta}$ which occur in the experiments, they may for this integration be treated as constants without introducing significant error. This is found to be true for the present work, and therefore performing these integrations with respect to $\theta$, equation (18) becomes

$$
\begin{gathered}
Q^{\prime \prime \prime}=\Delta M\left[\left(\sigma+\frac{d L}{d \theta}+u \frac{d \pi}{d \theta}\right)\left(-\theta_{1}+\frac{\mathrm{I}}{\Delta M} \int_{0}^{\Delta M} \theta_{\mathrm{e}} d M\right)\right. \\
+C^{\prime}{ }_{p} \frac{\mathrm{I}}{\Delta M} \int_{0}^{\Delta M}\left(\theta_{\mathrm{s}}-\theta_{\mathrm{e}}\right) d M
\end{gathered}
$$

If, furthermore, the experiment be performed in such a way that the vapor is withdrawn from the calorimeter at a constant rate then

$$
\frac{d M}{d t}=\frac{\Delta M}{\Delta t} \text { and hence } \frac{\mathrm{I}}{\Delta M} \int_{0}^{\Delta M} \theta d M=\frac{\mathrm{I}}{\Delta T} \int_{0}^{\Delta M} \theta d t
$$

where $\Delta t$ is the duration of the outflow. The values of $\frac{\mathrm{I}}{\Delta t} \int_{0}^{\Delta t} \theta_{\mathrm{e}} d t$ and $\frac{I}{\Delta t} \int_{0}^{\Delta t} \theta_{8} d t$ for any experiment may be obtained with sufficient accuracy from the periodic observations of these temperatures, and the above-mentioned condition of constant rate of outflow was approximately fulfilled in the present series of experiments. If the average values of $\theta_{\theta}$ and $\theta_{B}$ with regard to time be denoted by $\bar{\theta}_{\mathrm{e}}$, and $\bar{\theta}_{\mathrm{s}}$ and substituted for $\frac{\mathrm{I}}{\Delta M} \int_{0} \theta_{\mathrm{e}} d M$ and $\frac{\mathrm{I}}{\Delta M} \int_{0}^{\Delta M} \theta_{\mathrm{s}} d M$, respectively, in equation ( 14 ), this equation assumes the form

$$
Q^{\prime \prime \prime}=\Delta M\left[\left(\sigma+\frac{d L}{d \theta}+u \frac{d \pi}{d \theta}\right)\left(\bar{\theta}_{\mathrm{e}}-\theta_{1}\right)+C_{\mathrm{p}}^{\prime}\left(\bar{\theta}_{\mathrm{B}}-\bar{\theta}_{\mathrm{e}}\right)\right]
$$

which expresses the portion of the heat added, $Q^{\prime \prime \prime}$, which is determined by the conditions under which the evaporation and super- 
heating proceeds in the actual experiment. If the second member of this equation be substituted for the third and fourth terms of equation (I3), $\Delta Q$, the total quantity of heat added in the actual experiment may be substituted for $Q_{\mathrm{abc}}$, the total quantity of heat added in the assumed ideal case, and the resulting equation will be applicable to the observed data. In order to further simplify the equation and adapt it to numerical computation, the integration indicated in the fifth term should be performed. For this integration the function, $\left[\sigma+\theta \frac{d}{d \theta}\left(\frac{V}{M} \frac{d \pi}{d \theta}\right)-\theta \frac{d}{d \theta}\left(u \frac{d \pi}{d \theta}\right)\right]$, may without significant error be considered constant since it changes so slowly with temperature, and since the temperature change, $\theta_{2}-\theta_{1}$ was in every experiment made very small. By performing this integration and making the two aforementioned substitutions equation (I3) becomes:

$$
\begin{aligned}
\Delta Q=\Delta M & {\left[L_{1}+\left(\theta u \frac{d \pi}{d \theta}\right)_{1}+\left(\sigma+\frac{d L}{d \theta}+u \frac{d \pi}{d \theta}\right)\left(\overline{\theta_{\mathrm{e}}}-\theta_{1}\right)+C_{\mathrm{p}}^{\prime}\left(\overline{\theta_{\mathrm{s}}}-\overline{\theta_{\mathrm{e}}}\right)\right] } \\
& +M_{2}\left[\sigma+\theta \frac{d}{d \theta}\left(\frac{V}{M_{2}} \frac{d \pi}{d \theta}\right)-\theta \frac{d}{d \theta}\left(u \frac{d \pi}{d \theta}\right)\right]\left(\theta_{2}-\theta_{1}\right)
\end{aligned}
$$

Instead of completely solving this equation for $L_{1}$, by rearranging, and then substituting $\frac{L}{\theta} \frac{\mathrm{I}}{u^{\prime}-u}$ for $\frac{d \pi}{d \theta}$, the following equation, adapted to the numerical computation of $L_{1}$, is obtained:

$$
\begin{aligned}
L_{1}= & \frac{\Delta Q}{\Delta M}-L_{1} \frac{u_{1}}{u_{1}^{\prime}-u_{1}}-\left(\sigma+\frac{d L}{d \theta}+\frac{L}{\theta} \frac{u}{u^{\prime}-u}\right)\left(\overline{\theta_{\mathrm{e}}}-\theta_{1}\right)-C^{\prime}{ }_{p}\left(\overline{\theta_{\mathrm{s}}}-\overline{\theta_{\theta}}\right) \\
& -\left\{\frac{M_{2}}{\Delta M}\left[\sigma-\theta \frac{d}{d \theta}\left(\frac{L}{\theta} \frac{u}{u^{\prime}-u}\right)\right]+\frac{V}{\Delta M} \theta \frac{d}{d \theta}\left(\frac{L}{\theta} \frac{\mathrm{I}}{u^{\prime}-u}\right)\right\}\left(\theta_{2}-\theta_{1}\right)
\end{aligned}
$$

The expression, $\frac{\Delta Q}{\Delta M}-L_{1} \frac{u_{1}}{u^{\prime}{ }_{1}-u_{1}}$, in equation (22) represents the quantity of heat which would be added to the ammonia per gram evaporated at the initial temperature $\theta_{1}$. It would equal the latent heat of vaporization at that temperature if the experiment proceeded under ideal conditions, such that the heat added was instantaneously distributed over the free surface so as to avoid any change in temperature and pressure vhatever, for then all the other terms would vanish. The remaining terms in the right member of equation (22) represent corrections to the above expression for the departure of the actual experiment from the ideal conditions just specified above. 


\section{MATERIAL}

The ammonia used in these determinations was prepared by Messrs. McKelvy and Taylor, of the chemical division of this Bureau, by methods to be described in detail in an independent paper. A brief description of the process of preparation is here given.

The sample which was used in all the determinations of latent heat of evaporation and designated " $B$ " was prepared in May, I916, from commercial anhydrous ammonia manufactured by the synthetic method.

A sample was taken from, the original container by distillation into a steel container which would hold about a kilogram. From here it was transferred by distillation into a similar vessel containing metallic sodium to remove any remaining traces of water. Following this dehydration the purification was continued by from six to eight consecutive fractional distillations, rejecting in each distillation the first and last tenth. Removal of the rejected first fractions was performed in such a way as to extract the noncondensing gas present, either after vigorous shaking or during active boiling of the liquid.

Tests of the purified sample showed about I part in ro ooo by volume of noncondensing gases in the vapor phase, and about I part in 10 oco by weight of water.

\section{EXPERIMENTAL DETAILS}

Preparatory to a series of cleterminations, a quantity of ammonia was introduced into the calorimeter by distillation. The amount was determined by difference between the initial and final weight of the outside container. Enough was put in to bring the liquid surface near the top of the central tube which contained the heater. The baffle plates for insuring dryness of the vapor were entirely above the liquid. After introducing the ammonia, the large reservoir was replaced by a smaller one, more convenient for determining the amount of the portions withdrawn in the separate experiments. By use of the heating coil or special cooling device the calorimeter and contents were brought to the temperature chosen for a determination and the jacket brought under the control of the thermoregulator at the same temperature. The auxiliary thermoregulated bath in which the condenser was immersed was set at a temperature enough below the temperature of the calorimeter to provide a sufficient difference of vapor 
pressure to effect the desired rate of flow. The initial temperature of the calorimeter was determined by observing the resistance of one or both the platinum resistance thermometers. Initial readings were made of the manometer, the integrating thermocouples, and the auxiliary thermocouples on the outflow tubes. The valve in the outflow tube connecting to the condenser was opened, permitting the ammonia to distill from the calorimeter. Electric current was passed through the heating coil for a measured interval of time. During this interval alternate readings of current and potential drop were made periodically to determine the rate of energy supply to the calorimeter. In most experiments the energy was supplied continuously. In a few, however, in order to effect a variation in manner of manipulation, the current was interrupted occasionally and changed in order to control the conditions in the calorimeter.

During the experiment readings were made at equal intervals of time, of the manometer, the integrating thermocouples, and the auxiliary couples on the outflow tubes. These readings furnish a record of the pressure, the temperature of the vapor where it leaves the calorimeter, and the temperature difference between calorimeter and jacket which determines the thermal leakage. After the interruption of the heating current the evaporation and removal of ammonia was continued long enough to bring the temperature back approximately to the original temperature, and the valve then closed. After the practice obtained in a few preliminary experiments it was not difficult to keep the experimental conditions under satisfactory control so as to make the corrections for change from the initial temperature to the temperature of evaporation and to the final equilibrium temperature of calorimeter and contents sufficiently small. After the period of heating and removal of evaporated ammonia the calorimeter was allowed to repose long enough to come to a state of equilibrium and then readings were made of final equilibrium temperature and pressure. The reservoir was detached and reweighed, the mass removed being determined by difference. This program or procedure could be repeated in successive experiments until the ammonia in the calorimeter was so nearly exhausted as to necessitate refilling.

Considerable variation in the manipulation was possible and such variations were purposely introduced as a means of detecting possible systematic errors. Experiments were made in which the aim was to keep the temperature of evaporation as nearly as 
possible equal to the initial temperature. In these experiments the thermal leakage was relatively large. Usually the thermal leakage was kept small by keeping the average surface temperature of the calorimeter nearly constant, and permitting the temperature of evaporation to vary. Different rates of evaporation were used as a test for the dryness of the vapor, on the supposition that if spray were carried out with the vapor the amount would vary with the rate. Different parts of the heating coil were used, that part usually being used which would develop the heat nearest to the place where evaporation occurred.

The manometer as used constituted a vapor pressure thermometer, the readings of which determined the departure of the temperature of evaporation $\theta_{\mathrm{e}}$ from the initial temperature $\theta_{1}$. The variation in $\theta_{\theta}$ was never very large and the correction term in which it enters is small, consequently $\theta_{\mathrm{e}}$ need be known with only moderate precision.

The manometer was not jacketed and consequently its temperature was approximately that of the room. The changes in its temperature during any experiment were too small to produce a significant error in $\bar{\theta}_{\mathrm{e}}-\theta_{1}$. The lack of temperature control, however, precluded use of the manometer in experiments where the temperature $\theta_{\mathrm{e}}$ exceeded the temperature of the room because distillation would then have occurred. For these experiments, therefore, the value of $\bar{\theta}_{0}-\theta_{1}$ could not be directly observed. By noting that in the experiments where observed, $\bar{\theta}_{\mathrm{e}}-\theta_{1}$ seemed to be independent of the actual temperature, and that after the experimental technique had become fairly uniform the variations in this quantity in the range $-50^{\circ}$ to $+20^{\circ}$ were small, it was seen that the mean value for the range $+20^{\circ}$ to $+50^{\circ}$ could be assumed without serious uncertainty.

Some significant discrepancies in the earlier results were found to be due to the condensation of ammonia in the outflow tubes previous to beginning an experiment. Such an occurrence would result in transferring to the condenser more material than was evaporated during the period in which the heat added was measured and would therefore lead to a too low result for the latent heat of vaporization. This source of error was detected through the peculiarity that the initial experiment of a series frequently gave a result lower than those immediately following, the discrepancy in some cases being as much as 0.3 per cent. In order to ascertain that precondensation caused the error, special experi- 
ments were made which differed from the regular determinations in having the preliminary conditions such as to favor the condensation of ammonia in the tubes, and then evaporating a much smaller sample than usual so that the error, if due to this cause, would be proportionately increased. In this way the discrepancy from the normal value was so accentuated as to be four times as great as before, or about I.2 per cent. This result left no doubt as to the nature of the error, although additional confirmation was obtained by further investigation of the reasons why the means provided in the design of the calorimeter for avoiding this very difficulty had occasionally failed to accomplish the object.

Upon this occasion the discovery was made that the thermocouple leads entering the air space adjacent to the outflow tube provided a tiny avenue for the transfer of heat between the room outside and the central portion of the tube. It was thus possible for the temperature of this part of the outflow tube to assume a temperature differing from the temperature of the calorimeter in the same sense as the temperature of the room. Consequently, when the calorimeter was above the room in temperature, condensed ammonia would persist at this place, even though the part of the tube beyond was dried by means of the heating coils thereon. Upon applying heat by means of a coil to the conduit containing the leads, it was possible to overcome this defect and insure the complete drying of the outflow tube. However, the heat conveying ability of this path was so small that, although effective as a preventative measure during experiments, this remedy was not expeditious for expelling liquid, and for this purpose an equally effective and more convenient means was adopted, namely, to precede the first determination in a day's series with a blank experiment by which all liquid condensed in the outflow tube during the preliminary cooling would be expelled and the tube dried. The results of all previous initial experiments where this procedure had been omitted should, of course, be excluded from the authentic determinations because, even when operating at low temperatures, although the natural tendency would be for the tube ultimately to become dry, nevertheless there was no assurance that sufficient time had elapsed for this to occur, and therefore all unpreceded experiments in a series are open to doubt.

$59466^{\circ}-18-9$ 


\section{RESULTS OF MEASUREMENTS}

\section{CALORIMETRIC DATA}

The data ${ }^{13}$ obtained from the calorimetric measurements are given in Table $\mathrm{I} . \Delta Q$, the heat added to the ammonia, is computed according to the formula

$$
\Delta Q=\Sigma\left(I E t^{\prime}\right)+B h t_{2}-N\left(\Theta_{2}-\Theta_{1}\right)
$$

The total energy supplied electrically, $\Sigma\left(I E t^{\prime}\right)$, is the sum of the amounts for all the periods of heating during the experiment. In most of the experiments the energy was supplied during a single period $t^{\prime}$, the current, $I$, and potential drop, $E$, being very nearly constant, so that the product of the average values obtained from the periodic readings of the potentiometer multiplied by the time, $t^{\prime}$, gives the total energy within the limit of significant error. For the few experiments where the energy was supplied in several installments, each portion was computed separately and the sum taken. The thermal leakage was computed on the basis of the coefficient of thermal leakage, $B$, determined by supplementary experiments, the average deflection of the galvanometer, $h$, and the total time, $t_{2}$, elapsing between the initial and final readings of temperature $\theta_{1}$ and $\theta_{2}$. The energy absorbed by the calorimeter was computed on the basis of the heat capacity of the calorimeter, $N$, determined by supplementary experiments, ${ }^{14}$ and the total change in temperature, $\theta_{2}-\theta_{1}$, during the experiment.

13 The laboratory scale of temperature actually used in the measurements given in this paper is the scale of a resistance thermometer of Heraeus platinum of highest purity according to the equation

$$
\theta=\frac{R_{\theta}-R_{0}}{R_{100}-R_{0}} 100+\delta\left(\frac{\theta}{100}-1\right) \frac{\theta}{100}
$$

$R_{0}$ and $R_{100}$ are the resistances of the thermometer at the temperatures, under normal atmospheric pressure, of melting ice and saturated steam, respectively, and $\delta$ is determined by substituting for $R_{\theta}$ in the above equation the resistance of the thermoneter at the temperature of sulphur vapor under normal atmospheric pressure and 444.6 for $\theta$. The value of $\delta$ for the calorimeter thermometer was found by comparison with a standardized thermometer to be 1.48 . The departure of the scale so defined from the "thermodynamic" or "ideal gas" scale, down to $-50^{\circ} \mathrm{C}$ is not more than the limit of accuracy of existing gas thermometer data.

For all mathematical relations involving the second law of thermodynamics the temperatures are necessarily referred to the absolute zero. In recording laboratory data numerically it is usually convenient to use the ice point as zero. In the numerical tables of data and reductions no ambiguity arises on this account, as the experiments were conducced between $-50^{\circ}$ and $+50^{\circ}$ from the ice point, so that the recorded temperatures never numerically exceed $50^{\circ}$ while the absolute temperatures are never less than $200^{\circ}$.

Where numerical values are given, the joule used in this paper is determined by the relation $\frac{Q}{t}=\frac{E^{2}}{R}$, where $Q$ is the number of joules transformed into heat in a given electric circuit in $t$ seconds, $E$ the number of volts potential drop, and $R$ the number of ohms resistance; taking I volt $=\frac{I}{3.01830} \times$ emf of mean Weston normal cell at $20^{\circ} \mathrm{C}$, and I ohm $=$ resistance at $0^{\circ} \mathrm{C}$. of $106.300 \mathrm{~cm}$. of uniform mercury column $14.452 \mathrm{Ig}$. in mass. The difference between the international joule, realized thus, and the true joule is, according to present evidence, perhaps I part in 3000 . (B. S. Circular No. 60, Ist ed., p. 56; 1916.) The ampere is used only as an intermediary unit, being determined by the relation $I=\frac{E}{R}$, where $I=$ number of amperes.

14 This Bulletin, 14, p. 133; 1917. 
$\bar{\theta}_{\mathrm{e}}-\theta_{1}$ and $\bar{\theta}_{\mathrm{s}}$ are mean values of these temperatures obtained by averaging the readings taken periodically as explained in a previous section. In order to show how these temperatures varied during an experiment, the values of $\theta_{\mathrm{e}}$ and $\theta_{\mathrm{s}}$ during several experi-

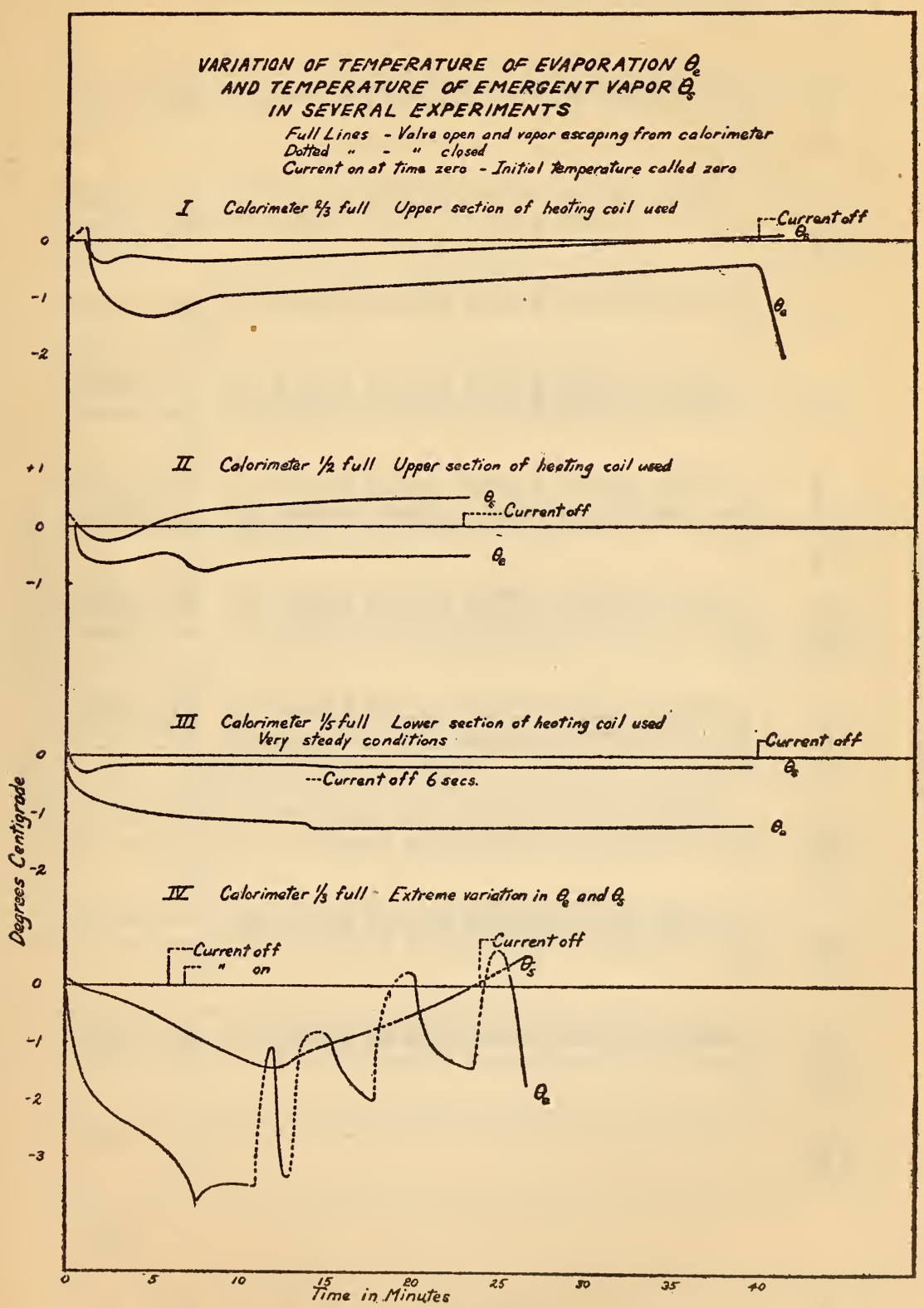

FIG. 2

ments were recorded graphically in Fig. 2. The other items in Table $\mathbf{I}$ are self-explanatory when taken in connection with Section VI on experimental procedure. 


\begin{tabular}{|c|c|c|}
\hline $1_{10}^{\circ}$ & 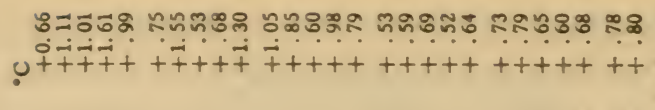 & 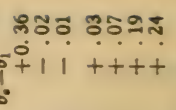 \\
\hline i. & 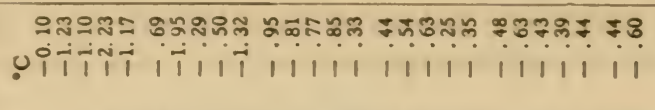 & \\
\hline & 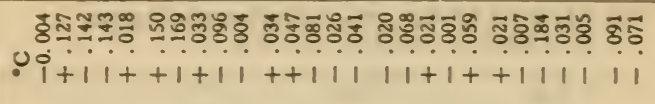 & 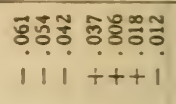 \\
\hline 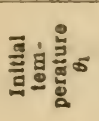 & 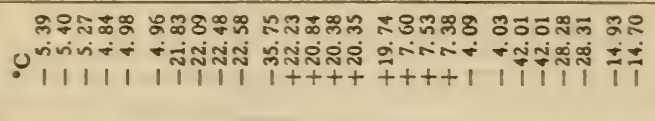 & 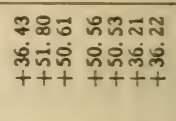 \\
\hline$>\sqrt{z}$ & 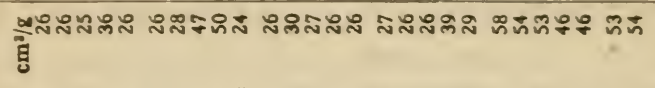 & 후눈 유유워 \\
\hline$\approx \frac{1}{4}$ & 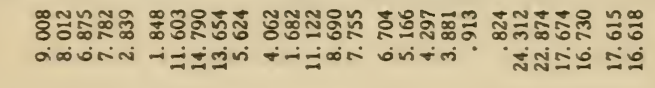 & 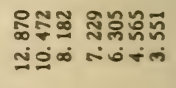 \\
\hline 可产 & 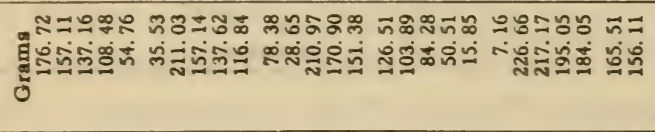 & 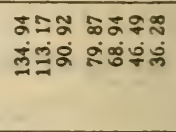 \\
\hline 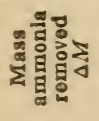 & 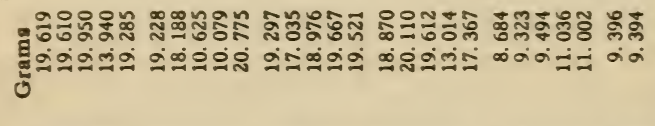 & 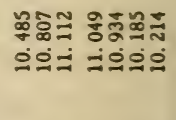 \\
\hline 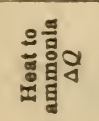 & 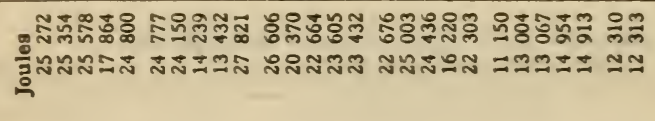 & 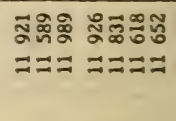 \\
\hline 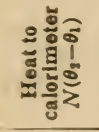 & 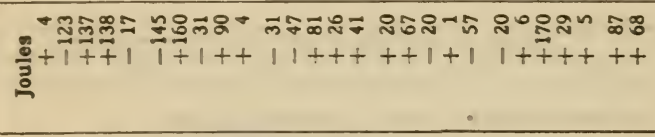 & 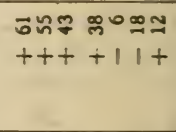 \\
\hline 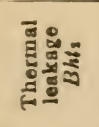 & 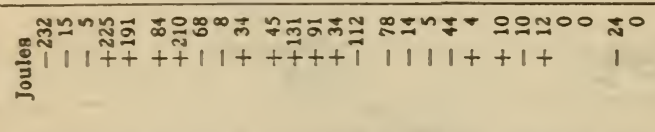 & $\begin{array}{l}\text { 9000m } 0 \text { m } \\
++111\end{array}$ \\
\hline 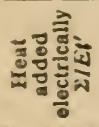 & 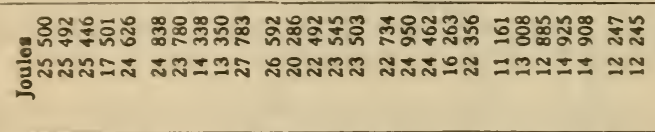 & 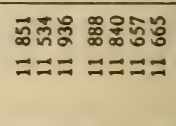 \\
\hline 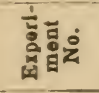 & NM TNN MNMNM NNNNM MNMNN BNMNM NM & NNNMOMO \\
\hline ดั & 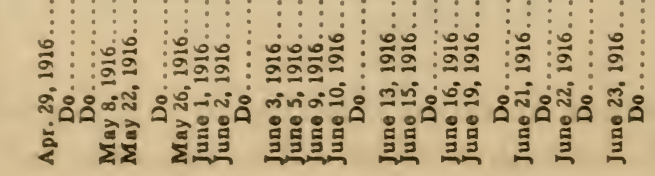 & 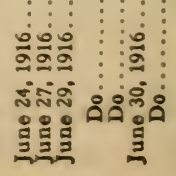 \\
\hline
\end{tabular}




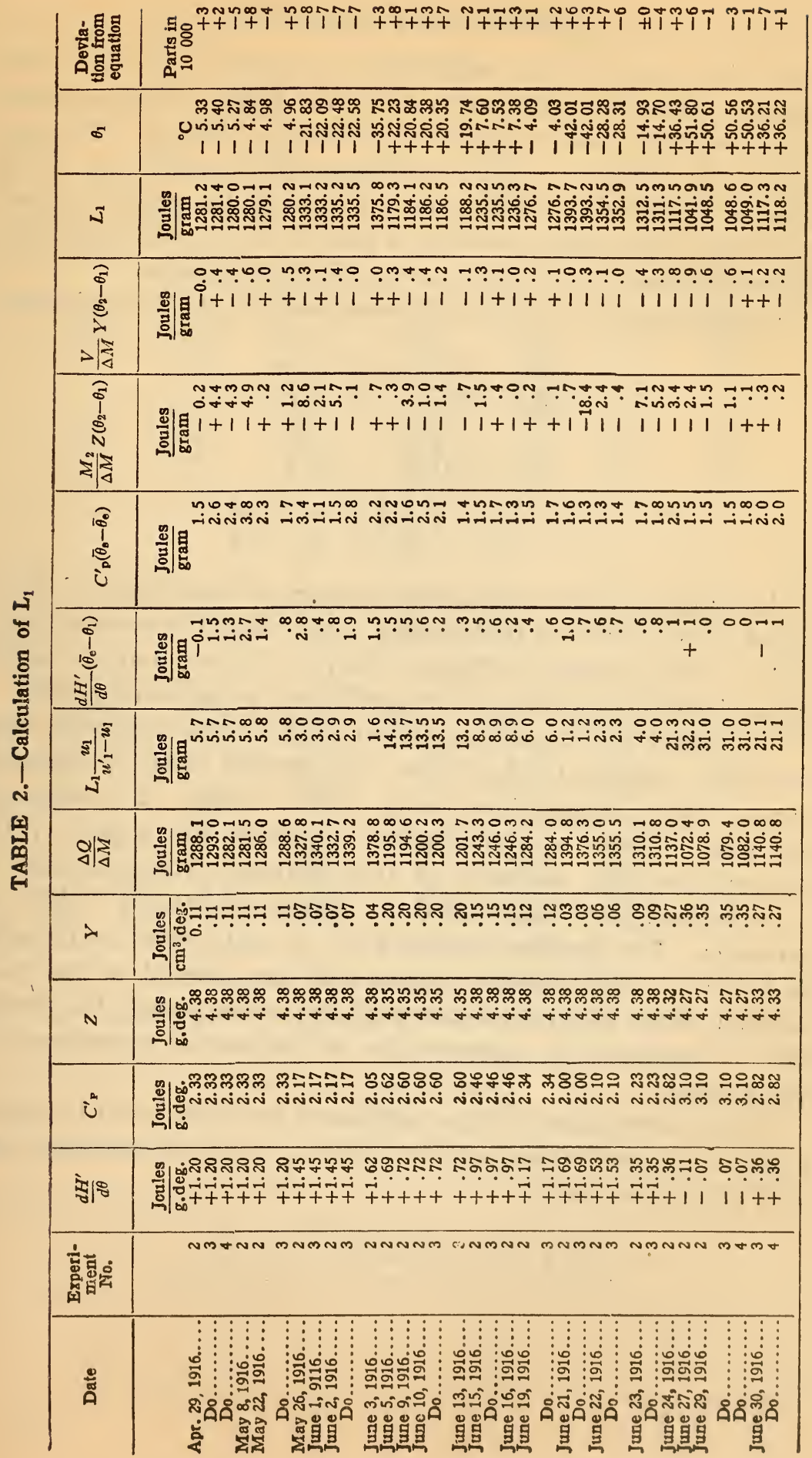




\section{COMPUTATION OF RESULTS}

In Table 2 is given the computation of the latent heat of vaporization, $L$, from the experimental data in Table $I$, and accessory data from other sources, suitably combined in Table 3 . The computation in Table 2 is made according to equation (22). This equation involves in addition to the data of the present experiments only the specific volumes $u$ and $u^{\prime}$ of the two phases and the specific heat $C^{\prime}$ of the vapor at constant pressure.

The following abbreviations are employed in the computations:

$$
\begin{aligned}
\frac{d H^{\prime}}{d \theta} & =\frac{d L}{d \theta}+\sigma+\frac{L}{\theta} \frac{u}{u^{\prime}-u} \\
Y & =\theta \frac{d}{d \theta}\left[\frac{L}{\theta} \frac{\mathrm{I}}{u^{\prime}-u}\right] \\
Z & =\sigma-\theta \frac{d}{d \theta}\left[\frac{L}{\theta} \frac{u}{u^{\prime}-u}\right]
\end{aligned}
$$

The values used for the specific volumes of the liquid and vapor phases of ammonia are preliminary values from the measurements made at this Bureau by Messrs. Harper, Cragoe, and O'Connor, the final results of which will be published in a separate paper.

The values of $C^{\prime}$ p used are provisional values computed from Nernst's ${ }^{15}$ empirical formula for the specific heat of ammonia vapor. This computation was made, using a previously described ${ }^{16}$ form of characteristic equation for a gas, by Dr. Thadee Peczalski, formerly of this Bureau. The constants in the equation were determined by means of Holst's ${ }^{17}$ data on ammonia. The limiting values of $C^{\prime}{ }_{p}$ at saturation are included in Table 2. Approximate values only are needed in the computation of the small correction term and consequently the change due to variation in temperature in the actual experiment is disregarded.

In the computation of the coefficients in Table 3 and the interpolation for the values used in Table 2, graphical methods were used where convenient.

15 Nernst, Zeitschr. f. Elektrochemie, 17, p. 49; 1910.

${ }_{16}$ Ann. de Phys. (9), 1, p. 457; 1914.

${ }^{17}$ Holst, Bull. Assn. Internationale du Froid (51); ror5. 
TABLE 3.-Supplementary Computation of Coefficients $\frac{\mathrm{d} H^{\prime}}{\mathrm{d} \theta}, \mathrm{Y}$, and $Z$, from Accessory Data

\begin{tabular}{|c|c|c|c|c|c|c|c|c|}
\hline 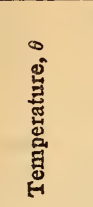 & 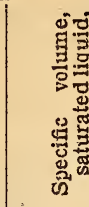 & & 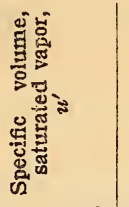 & $=\left.\right|_{i} ^{3}$ & 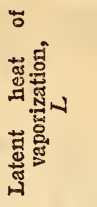 & $=\int_{i}^{3}$ & 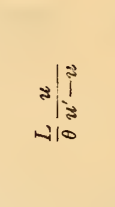 & 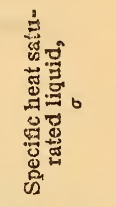 \\
\hline $\begin{array}{r}{ }^{\circ} \mathbf{C} \\
-50 \\
-40 \\
-30 \\
-20 \\
-10\end{array}$ & $\frac{\mathrm{cr}}{\mathrm{g}}$ & $\begin{array}{l}1.424 \\
1.449 \\
1.475 \\
1.503 \\
1.533\end{array}$ & $\begin{array}{l}\frac{\mathrm{cm}^{3}}{\mathrm{~g}_{\mathbf{0}}} \\
2550 \\
1514 \\
941 \\
612.3 \\
414.0\end{array}$ & $\begin{array}{r}0.00056 \\
.00096 \\
.00157 \\
.00246 \\
.00372\end{array}$ & $\begin{array}{l}\text { Joules } \\
\text { g. } \\
1413 \\
1387 \\
1358 \\
1329 \\
1298\end{array}$ & \begin{tabular}{c} 
Joules \\
\multicolumn{1}{c}{ g. 0.79} \\
1.33 \\
2.13 \\
3.27 \\
4.83
\end{tabular} & $\begin{array}{l}\text { Joules } \\
\text { g.deg. } \\
0.0035 \\
.0057 \\
.0088 \\
.0129 \\
.0184\end{array}$ & \multirow{2}{*}{\begin{tabular}{r} 
Joules \\
\multicolumn{1}{c}{ g.cieg. } \\
4.41 \\
4.44 \\
4.47 \\
4.51 \\
4.55 \\
\\
4.60 \\
4.65 \\
4.71 \\
4.78 \\
4.86 \\
4.96
\end{tabular}} \\
\hline $\begin{array}{r}0 \\
+10 \\
+20 \\
+30 \\
+40 \\
+50\end{array}$ & & $\begin{array}{l}1.566 \\
1.601 \\
1.638 \\
1.679 \\
1.725 \\
1.776\end{array}$ & $\begin{array}{r}288.7 \\
205.0 \\
148.0 \\
110.1 \\
82.8 \\
63.0\end{array}$ & $\begin{array}{l}.00545 \\
.00787 \\
.01119 \\
.01548 \\
.02128 \\
.02901\end{array}$ & $\begin{array}{l}1263 \\
1228 \\
1190 \\
1147 \\
1100 \\
1051\end{array}$ & $\begin{array}{r}6.88 \\
9.66 \\
13.32 \\
17.76 \\
23.41 \\
30.49\end{array}$ & $\begin{array}{l}.0252 \\
.0341 \\
.0455 \\
.0586 \\
.0748 \\
.0944\end{array}$ & \\
\hline 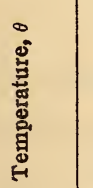 & ్ㅣ|శి & స్త| & $\sqrt{\sqrt[3]{\frac{5}{3}}}$ & 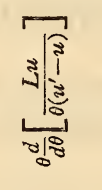 & $\frac{\sqrt{3}}{\underbrace{3}_{0}}$ & $\sqrt{\frac{8}{3}}$ & $\frac{\sqrt{\frac{\pi}{2}}}{\sqrt{\frac{\pi}{3}}}$ & $\sqrt{\sqrt{3}}$ \\
\hline $\begin{array}{l}{ }^{\circ} \mathbf{C} \\
-50 \\
-40 \\
-30 \\
-20 \\
-10\end{array}$ & $\begin{array}{r}\text { Joules } \\
\text { g.deg. } \\
-2.63 \\
-2.77 \\
-2.93 \\
-3.11 \\
-3.30\end{array}$ & $\begin{array}{l}\text { Joules } \\
\text { g.deg. } \\
+1.78 \\
+1.68 \\
+1.55 \\
+1.41 \\
+1.27\end{array}$ & $\begin{array}{l}\text { Joules } \\
\text { g. deg. } \\
0.00019 \\
.00026 \\
.00036 \\
.00047 \\
.00060\end{array}$ & $\begin{array}{r}\text { Joules } \\
\text { g.deg. } \\
0.04 \\
.06 \\
.09 \\
.12 \\
.16\end{array}$ & $\begin{array}{r}\text { Joules } \\
\text { g.deg. } \\
4.37 \\
4.38 \\
4.38 \\
4.39 \\
4.39\end{array}$ & $\begin{array}{r}\text { Joules } \\
\mathrm{cm}^{3} \text {.deg. } \\
0.0025 \\
.0039 \\
.0060 \\
.0086 \\
.0120\end{array}$ & $\begin{array}{r}\text { Joules } \\
\text { cm }^{3} \text {.deg. } \\
0.00011 \\
.00017 \\
.00023 \\
.00030 \\
.00037\end{array}$ & \multirow{2}{*}{ 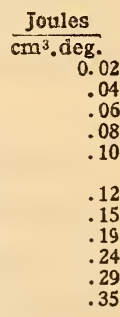 } \\
\hline $\begin{array}{r}0 \\
+10 \\
+20 \\
+30 \\
+40 \\
+50\end{array}$ & $\begin{array}{l}-3.51 \\
-3.75 \\
-4.02 \\
-4.33 \\
-4.68 \\
-5.10\end{array}$ & $\begin{array}{l}+1.12 \\
+0.93 \\
+0.74 \\
+0.51 \\
+0.25 \\
-0.05\end{array}$ & $\begin{array}{l}.00977 \\
.00097 \\
.00120 \\
.00149 \\
.00180 \\
.00215\end{array}$ & $\begin{array}{l}.21 \\
.27 \\
.35 \\
.45 \\
.56 \\
.69\end{array}$ & $\begin{array}{l}4.39 \\
4.38 \\
4.36 \\
4.33 \\
4.30 \\
4.27\end{array}$ & $\begin{array}{l}.0161 \\
.0213 \\
.0278 \\
.0349 \\
.0433 \\
.0532\end{array}$ & $\begin{array}{l}.00045 \\
.00054 \\
.00065 \\
.00078 \\
.00092 \\
.00107\end{array}$ & \\
\hline
\end{tabular}

For the experiments where $\theta_{e}-\theta_{1}$ was not observed on account of the temperature being higher than would allow the use of the manometer, the value of $\bar{\theta}_{\theta}-\theta_{1}$ was taken equal to $0.5^{\circ}$, this being the mean value in previous experiments. The greatest deviation from this value in the preceding experiments was not more than $0.3^{\circ}$, and this amount would not change the computed value of $L$ more than I part in Iooo. The final results probably are affected less than one-third this amount.

Except for 23 experiments, which were excluded on account of liability to error due to precondensation (see Sec. VI) and a very few others in which incomplete records were obtained, all the experiments made are included in Tables $\mathrm{I}$ and 2. All experiments discredited for reasons previously given may be found in Table 4 . 
TABLE 4.-Experiments Discredited on Account of Precondensation

\begin{tabular}{|c|c|c|c|c|c|c|c|c|c|}
\hline Date & $\begin{array}{l}\text { Ex- } \\
\text { peri- } \\
\text { ment } \\
\text { No. }\end{array}$ & $\begin{array}{l}\text { Tem- } \\
\text { pera- } \\
\text { ture, } \\
\theta\end{array}$ & $\begin{array}{l}\text { Heat of } \\
\text { vapori- } \\
\text { zation, } \\
L\end{array}$ & $\begin{array}{l}\text { De- } \\
\text { via- } \\
\text { tlon } \\
\text { from } \\
\text { equa- } \\
\text { tion }\end{array}$ & Date & $\begin{array}{c}\text { Ex- } \\
\text { peri- } \\
\text { ment } \\
\text { No. }\end{array}$ & $\begin{array}{l}\text { Tem- } \\
\text { pera- } \\
\text { ture, } \\
\quad \theta\end{array}$ & $\begin{array}{l}\text { Heat of } \\
\text { vaporl- } \\
\text { zation, } \\
L\end{array}$ & $\begin{array}{l}\text { De- } \\
\text { via- } \\
\text { tion } \\
\text { from } \\
\text { equa- } \\
\text { tion }\end{array}$ \\
\hline $\begin{array}{l}\text { Apr. } 28,1916 \ldots \ldots \\
\text { Apr. } 29,1916 \ldots \ldots \\
\text { May } 8,1916 \ldots \ldots \\
\text { May } 22,1916 . \ldots . \\
\text { May } 23,1916 \ldots . .\end{array}$ & $\begin{array}{l}1 \\
1 \\
1 \\
1 \\
1\end{array}$ & $\begin{array}{c}{ }^{\circ} \mathrm{C} \\
-5.37 \\
-5.33 \\
-4.96 \\
-4.97 \\
-4.96\end{array}$ & $\begin{array}{l}\text { Joules } \\
\text { gram } \\
1278.8 \\
1279.5 \\
1279.5 \\
1278.4 \\
1279.2\end{array}$ & $\begin{array}{c}\text { Parts } \\
\text { in } \\
10 \quad 000 \\
-16 \\
-10 \\
\pm \quad 0 \\
=\quad 9 \\
-\quad 2\end{array}$ & $\begin{array}{r}\text { June } 10,1916 \ldots . . \\
\text { June } 13,1916 . . . \\
\text { Do.......... }\end{array}$ & $a \begin{array}{r}1 \\
1 \\
2 \\
1\end{array}$ & $\begin{array}{c}{ }^{\circ} \mathrm{C} \\
+20.38 \\
+19.84 \\
+19.82 \\
+7.32\end{array}$ & $\begin{array}{l}\text { Joules } \\
\text { gram } \\
1183.0 \\
1185.3 \\
1173.9 \\
1235.6\end{array}$ & $\begin{array}{l}\text { Parts } \\
\text { in } \\
10000 \\
-24 \\
-\quad 23 \\
-120 \\
-\quad 4\end{array}$ \\
\hline $\begin{array}{l}\text { May } 29,1916 \ldots \ldots \\
\text { June } 1,1916 \ldots \ldots \\
\text { June } 2,1916 \ldots \ldots \\
\text { June } 3,1916 \ldots \ldots \\
\text { June } 5,1916 \ldots \ldots\end{array}$ & $\begin{array}{l}1 \\
1 \\
1 \\
1 \\
1\end{array}$ & $\begin{array}{l}-21.27 \\
-22.05 \\
-22.51 \\
-35.80 \\
+22.28\end{array}$ & $\begin{array}{l}1332.8 \\
1335.4 \\
1335.6 \\
1375.8 \\
1176.0\end{array}$ & $\begin{array}{r}+2 \\
+\quad 4 \\
\pm \quad 5 \\
+\quad 2 \\
-18\end{array}$ & $\begin{array}{l}\text { June } 19,1916 \ldots . . \\
\text { June } 22,1916 \ldots \ldots \\
\text { June } 23,1916 \ldots \ldots \\
\text { June } 24,1916 \ldots \ldots\end{array}$ & $\begin{array}{l}1 \\
1 \\
1 \\
1\end{array}$ & $\begin{array}{r}-4.24 \\
-28.24 \\
-14.73 \\
+36.49 \\
+51.92\end{array}$ & $\begin{array}{l}1275.7 \\
1352.5 \\
1310.4 \\
1115.8\end{array}$ & $\begin{array}{l}-11 \\
=\quad 8 \\
=11 \\
-10 \\
-19\end{array}$ \\
\hline $\begin{array}{l}\text { June } 6,1916 . \\
\text { June } 9,1916 .\end{array}$ & $\begin{array}{l}1 \\
1\end{array}$ & $\begin{array}{r}+22.24 \\
+22.24 \\
+20.86\end{array}$ & $\begin{array}{l}1178.2 \\
1180.4\end{array}$ & $\begin{array}{r}1 \\
-30\end{array}$ & & $\begin{array}{l}1 \\
1 \\
1\end{array}$ & & & \\
\hline
\end{tabular}

a Precondensation induced.

\section{FORM OF EMPIRICAL EQUATION}

An empirical equation the form of which is consistent with the behavior of substances at the critical point should give a value of zero at the critical point for $L$, and for the derivative $\frac{d L}{d \theta}$ should give a value of $-\infty$. An equation of the form

$$
L=A\left(\theta_{\mathrm{c}}-\theta\right)+B\left(\theta_{\mathrm{c}}-\theta\right)^{1 / 2}
$$

in which $\theta_{0}=$ the critical temperature, was found to meet these requirements and to represent the experimental results closely. The equation has the further advantage of giving no real roots above the critical temperature.

\section{DISCUSSION OF RESULTS}

Table 5 contains the results of all the reliable experiments and the additional data regarding variation in the experimental conditions.

This table is given for the purpose of showing the manner in which the conditions were varied and the effect produced upon the results. The following conditions which might conceivably independently affect the results are shown: (a) Rate of evaporation; (b) thermal leakage; (c) average deviation of evaporation temperature from initial temperature; $(d)$ maximum deviation of evaporation temperature from initial temperature; $(e)$ portion of heating coil used; $(f)$ amount removed; $(g)$ amount in calorimeter (mean during experiment); and $(h)$ temperature of experiment. 


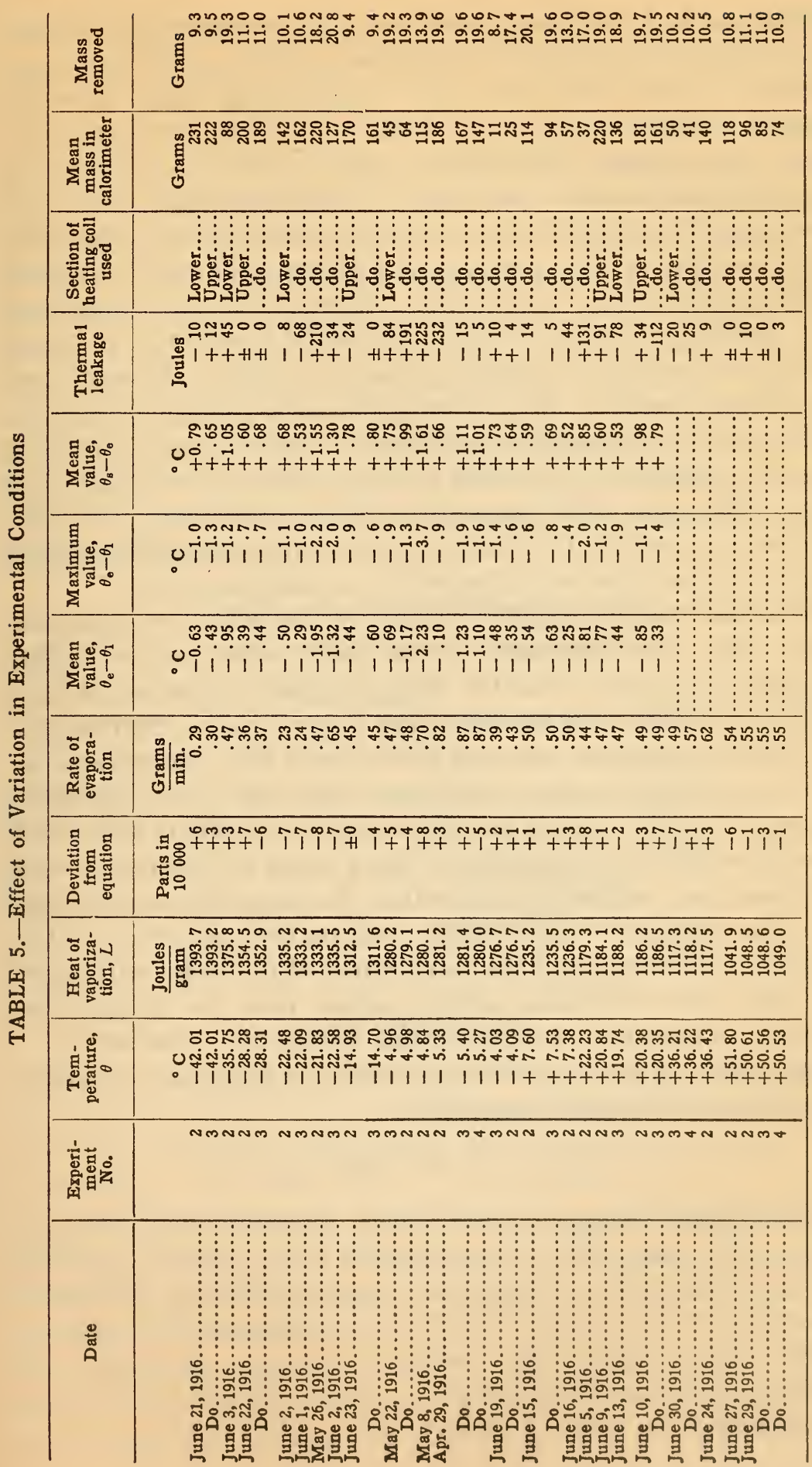


These various conditions were not all systematically changed one at a time, keeping all the others constant, as would have been necessary if large variations had been found to result from the changes. Except for the actual temperature of the determination, which is the primary independent variable, effects of variations in the other conditions are presumed to have been either eliminated experimentally or taken into account quantitatively in the computation of the results, supposing, of course, that such variations were kept within reasonable limits. If the results were dependent to a significant extent on these incidental conditions, it would scarcely be possible to combine them as in Table 5 without some effect being observed. By examination of the deviations from the value given by the empirical equation it has not been possible to trace any systematic deviation to any of the experimental conditions other than the temperature of the experiment. It may, therefore, be concluded that no systematic error resulted from these conditions which was not obscured by accidental errors.

Particular mention might be made of the rate of evaporation. If this rate were increased to the point where active boiling occurred, it is possible that the system of baffle plates might have failed to intercept all of the fine spray thrown up and the evaporation of the withdrawn material would have been incomplete, or, in other words, the vapor would have been wet. It is, therefore, of especial interest to note the considerable variation in rate which occurred without any consequent effect upon the resulting value for latent heat, indicating that within the range of variation used the vapor was dry. Additional confirmation on this point is furnished by the fact that the temperature of the vapor withdrawn was, with rare exceptions, always higher than the temperature at which evaporation was proceeding within the calorimeter.

The results of the determinations may be expressed by means of the following empirical equation:

$$
L=137.9 \mathrm{I} \sqrt{133-\theta}-2.466(\mathrm{I} 33-\theta)
$$

By assigning average and maximum fortuitous errors to each element that enters into a determination it is possible to estimate the magnitude of the corresponding resultant errors in the heat of vaporization. The average fortuitous error estimated in this way should, of course, agree with the observed average deviation from the mean curve, and the observed maximum error should not exceed the estimated. It is also possible to estimate the systematic errors 
introduced by the uncertainty of the accessory data used in the calculation of the latent heat, and in so doing get some idea of the accuracy of the experiments.

In Table 6 will be found such a tabulation of estimated errors, both fortuitous and systematic, together with the average deviations of the experiments from the mean curve. It will be seen that the agreement between the observed and estimated average fortuitous error is very satisfactory, which means that by a good fortune unusual in calorimetry the precision attained in the results was that to be expected from the precision of the various factors. The observed maximum fortuitous error is much less than the calculated, as might very well happen in a limited number of experiments where there is little chance of all the errors occurring in any one. It will also be noted that the total estimated etrors, both fortuitous and systematic, are practically the same as those due to accident alone.

TABLE 6.-Latent Heat of Vaporization $\mathrm{NH}_{3}$

[Discussion of Errors. Parts in 10000 produced in I]

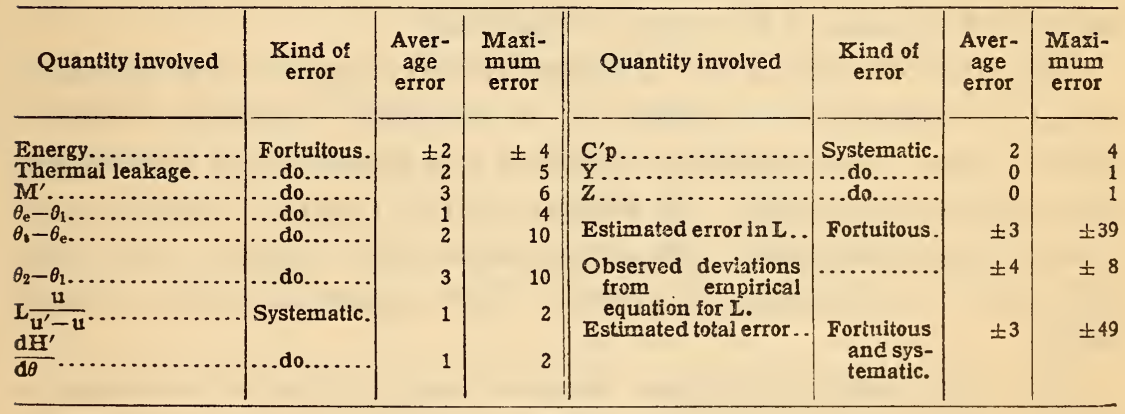

\section{SUMMARY}

Using a calorimeter of the aneroid type specially designed for the peculiar conditions, the latent heat of vaporization of ammonia has been determined throughout the temperature interval -42 to $+52^{\circ} \mathrm{C}$.

A detailed description of the design and construction of the instrument having been given in a separate paper, only a brief description of the apparatus is included here, the theory of the method and the experimental details, however, being discussed. The instrument contains no special liquid for a calorimetric medium, the ammonia being the only liquid in the calorimeter. 
Heat developed and measured electrically in a coil is transmitted by conduction and convection to the surrounding ammonia and is utilized to effect the evaporation of a determined amount of the ammonia which is withdrawn as superheated vapor at a determined temperature and pressure. Heat from other sources is minimized by reducing as far as practicable the avenues for heat transfer between the calorimeter and its environment, and by so manipulating as to keep the temperatures of the calorimeter and jacket surfaces nearly equal, means being provided for determining the amount of thermal leakage which is not thus annulled. Initial and final temperatures are measured by a platinum resistance thermometer.

An analysis of the process occurring in the calorimeter during an experiment leads to a method of calculation of the results whereby data from other sources than the direct calorimetric observations enter only in the computation of correction terms which can by careful manipulation be made small.

Variations in manipulation were introduced as a means of detecting possible systematic errors, particularly in regard to the matter of dryness of the vapor withdrawn.

The result of each of the 34 determinations agrees with the mean result as expressed by means of an empirical equation within I part in rooo. An empirical equation was found which in addition to representing closely the results in the range of temperature covered experimentally, also conforms to what is known about the behavior of substances in general when approaching the critical point.

As a final result the latent heat of vaporization of ammoniathat is, the heat in joules per gram required to convert saturated liquid into saturated vapor at constant temperature-is expressed in the range $-42^{\circ}$ to $+52^{\circ} \mathrm{C}$ by the equation:

$$
L=\mathrm{I} 37.9 \mathrm{I} \sqrt{\mathrm{I} 33-\theta}-2.466 \text { ( } 33-\theta) .
$$

If the latent heat of vaporization be expressed in calories ${ }_{20}$ per gram, taking I calorie $e_{20}=4.183$ joules, the equation becomes

$$
L=32.968 \sqrt{133-\theta}-0.5895(\mathrm{I} 33-\theta) .
$$


The values computed from this equation every 5 degrees are as follows:

\begin{tabular}{|c|c||c|c|}
\hline Temperature & $\begin{array}{c}\text { Latent heat } \\
\text { of } \\
\text { vaporization }\end{array}$ & Temperature & $\begin{array}{c}\text { Latent heat } \\
\text { of } \\
\text { vaporization }\end{array}$ \\
\cline { 2 - 3 }${ }^{\circ} \mathrm{C}$ & calories/g & ${ }^{\circ} \mathrm{C}$ & calories/g \\
-45 & 334.9 & +5 & 297.5 \\
-40 & 331.7 & +10 & 293.1 \\
-35 & 328.3 & +15 & 288.6 \\
-30 & 324.8 & +20 & 283.8 \\
-25 & 321.3 & +25 & 278.9 \\
-20 & 317.6 & +30 & 273.9 \\
-15 & 313.8 & +35 & 268.6 \\
-10 & 309.9 & +40 & 263.1 \\
-5 & 305.9 & +45 & 257.4 \\
0 & 301.8 & +50 & 251.4 \\
& & +55 & 245.1 \\
\hline
\end{tabular}

WASHINGTON, May I, I9I 7 . 


\section{APPENDIXES}

\section{APPENDIX 1.-LATENT HEAT OF VAPORIZATION OF AMMONIA}

CALORIES PER GRAM

\begin{tabular}{c|c|c|c|c|c|c|c|c|c|c}
\hline $\begin{array}{c}\text { Tempera- } \\
\text { ture }\end{array}$ & 0 & 1 & 2 & 3 & 4 & 5 & 6 & 7 & 8 & 9 \\
\cline { 1 - 6 }${ }^{\circ} \mathrm{C}$ & & & & & & & & & & \\
-40 & 331.7 & 332.3 & 333.0 & 333.6 & 334.3 & 334.9 & 335.5 & 336.2 & 336.8 & 337.5 \\
-30 & 324.8 & 325.5 & 326.2 & 326.9 & 327.6 & 328.3 & 329.0 & 329.7 & 330.3 & 331.0 \\
-20 & 317.6 & 318.3 & 319.1 & 319.8 & 320.6 & 321.3 & 322.0 & 322.7 & 323.4 & 324.1 \\
-10 & 309.9 & 310.7 & 311.5 & 312.2 & 313.0 & 313.8 & 314.6 & 315.3 & 316.1 & 316.8 \\
-0 & 301.8 & 302.6 & 303.4 & 304.3 & 305.1 & 305.9 & 306.7 & 307.5 & 308.3 & 309.1 \\
+0 & 301.8 & 300.9 & 300.1 & 299.2 & 298.4 & 297.5 & 296.6 & 295.7 & 294.9 & 294.0 \\
+10 & 293.1 & 292.2 & 291.3 & 290.4 & 289.5 & 288.6 & 287.6 & 286.7 & 285.7 & 284.8 \\
+20 & 283.8 & 282.8 & 281.8 & 280.9 & 279.9 & 278.9 & 277.9 & 276.9 & 275.9 & 274.9 \\
+30 & 273.9 & 272.8 & 271.8 & 270.7 & 269.7 & 268.6 & 267.5 & 266.4 & 265.3 & 264.2 \\
+40 & 263.1 & 262.0 & 260.8 & 259.7 & 258.5 & 257.4 & 256.2 & 255.0 & 253.8 & 252.6 \\
\hline
\end{tabular}

BTU PER POUND

\begin{tabular}{c|l|l|l|l|l|l|l|l|l|l}
\hline${ }^{\circ} \mathbf{F}$ & & & & & & & & & & \\
-40 & 597.0 & 597.7 & 598.3 & 599.0 & 599.6 & 600.3 & 600.9 & 601.6 & 602.2 & 602.9 \\
-30 & 590.2 & 590.9 & 591.6 & 592.3 & 592.9 & 593.6 & 594.3 & 595.0 & 595.6 & 596.3 \\
-20 & 583.3 & 584.0 & 584.7 & 585.4 & 586.1 & 586.8 & 587.5 & 588.1 & 588.8 & 589.5 \\
-10 & 576.1 & 576.8 & 577.6 & 578.3 & 579.0 & 579.7 & 580.4 & 581.1 & 581.9 & 582.6 \\
-0 & 568.7 & 569.4 & 570.2 & 570.9 & 571.7 & 572.4 & 573.2 & 573.9 & 574.6 & 575.4 \\
+0 & 568.7 & 567.9 & 567.2 & 566.4 & 565.7 & 564.9 & 564.1 & 563.3 & 562.6 & 561.8 \\
+10 & 561.0 & 560.2 & 559.5 & 558.7 & 557.9 & 557.1 & 556.3 & 555.5 & 554.7 & 553.9 \\
+20 & 553.1 & 552.3 & 551.5 & 550.7 & 549.9 & 549.1 & 548.2 & 547.4 & 546.6 & 545.8 \\
+30 & 544.9 & 544.1 & 543.3 & 542.4 & 541.6 & 540.7 & 539.9 & 539.0 & 538.2 & 537.3 \\
+40 & 536.5 & 535.6 & 534.7 & 533.8 & 533.0 & 532.1 & 531.2 & 530.3 & 529.5 & 528.6 \\
+50 & 527.7 & 526.8 & 525.9 & 524.9 & 524.0 & 523.1 & 522.2 & 521.2 & 520.3 & 519.4 \\
+60 & 518.5 & 517.5 & 516.6 & 515.6 & 514.7 & 513.7 & 512.8 & 511.8 & 510.9 & 509.9 \\
+70 & 508.9 & 508.0 & 507.0 & 506.0 & 505.0 & 504.1 & 503.1 & 502.1 & 501.1 & 500.1 \\
+80 & 499.1 & 498.1 & 497.0 & 496.0 & 495.0 & 494.0 & 493.0 & 491.9 & 490.9 & 489.8 \\
+90 & 488.8 & 487.7 & 486.7 & 485.6 & 484.6 & 483.5 & 482.4 & 481.3 & 480.2 & 479.1 \\
+100 & 478.0 & 476.9 & 475.8 & 474.7 & 473.6 & 472.5 & 471.3 & 470.2 & 469.0 & 467.9 \\
+110 & 466.7 & 465.6 & 464.4 & 463.3 & 462.1 & 460.9 & 459.7 & 458.5 & 457.3 & 456.1 \\
\hline
\end{tabular}




\section{APPENDIX 2.-SPECIFIC HEAT OF SATURATED AMMONIA VAPOR}

If the latent heat of vaporization and the specific heat of the saturated liquid are known as functions of the temperature, it is possible to compute the specific heat of the saturated vapor by using the general relation

$$
\sigma^{\prime}-\sigma=\frac{d L}{d \theta}-\frac{L}{\theta}=\theta \frac{d}{d \theta}\left(\frac{L}{\theta}\right)
$$

The data for the specific heat of saturated liquid ammonia are available from a previous investigation ${ }^{18}$ the results of which are expressed by the empirical equation

$$
\sigma=3.1365-0.00057 \theta+\frac{16.842}{\sqrt{133-\theta}}
$$

in which $\sigma$ is the specific heat in joules per gram degree at temperature $\theta$ of the saturated liquid. The rate of change $\frac{d L}{d \theta}$ of the heat of vaporization of ammonia with temperature and the quantity $\frac{L}{\theta}$ can be calculated from the results of the present work. The computed values of the specific heat $\sigma^{\prime}$ in joules per gram degree of

\begin{tabular}{|c|c|c|c|}
\hline Temperature & $\begin{array}{l}\text { Specific heat } \\
\text { of saturated } \\
\text { vapor }\end{array}$ & Temperature & $\begin{array}{l}\text { Specific heat } \\
\text { of saturated } \\
\text { vapor }\end{array}$ \\
\hline $\begin{array}{l}{ }^{\circ} \mathrm{C} \\
-45 \\
-40 \\
-35 \\
-30 \\
-25\end{array}$ & $\begin{array}{c}\text { Joules/g deg. } \\
-4.42 \\
-4.29 \\
-4.17 \\
-4.05 \\
-3.95\end{array}$ & $\begin{array}{l}{ }^{\circ} \mathrm{C} \\
\quad 0 \\
+5 \\
+10 \\
+15 \\
+20\end{array}$ & $\begin{array}{c}\text { Joules/g deg. } \\
-3.54 \\
-3.48 \\
-3.43 \\
-3.40 \\
-3.36\end{array}$ \\
\hline $\begin{array}{r}-20 \\
-15 \\
-10 \\
-5 \\
0\end{array}$ & $\begin{array}{r}-3.85 \\
-3.76 \\
-3.68 \\
-3.61 \\
-3.54\end{array}$ & $\begin{array}{l}+25 \\
+30 \\
+35 \\
+40 \\
+45\end{array}$ & $\begin{array}{l}-3.34 \\
-3.33 \\
-3.33 \\
-3.34 \\
-3.36\end{array}$ \\
\hline
\end{tabular}
saturated ammonia vapor are given in the following table:

18 This Bulletin, 14, p. 397; $19 \times 7$. 


\section{APPENDIX 3.-HEAT OF VAPORIZATION OF AMMONIA IN CALORIES 20 PER GRAM COMPUTED BY VARIOUS WRITERS AND GIVEN IN THEIR AMMONIA TABLES}

[The results of the present work are included for comparison]

\begin{tabular}{|c|c|c|c|c|c|c|c|c|}
\hline \multicolumn{2}{|c|}{ Temperature } & \multirow{2}{*}{$\begin{array}{c}\text { Ledoux, } \\
1878\end{array}$} & \multirow{2}{*}{$\begin{array}{c}\text { Peabody, } \\
1889\end{array}$} & \multirow{2}{*}{$\begin{array}{l}\text { Wood, } \\
1889\end{array}$} & \multirow{2}{*}{$\begin{array}{c}\text { Zeuner, } \\
1890\end{array}$} & \multirow{2}{*}{$\begin{array}{c}\text { Mollier, } \\
1895\end{array}$} & \multirow{2}{*}{$\begin{array}{c}\text { Dieterici, } \\
1904\end{array}$} & \multirow{2}{*}{$\begin{array}{c}\text { Wobsa, } \\
1908\end{array}$} \\
\hline${ }^{\circ} \mathrm{F}$ & ${ }^{\circ} \mathrm{C}$ & & & & & & & \\
\hline $\begin{array}{l}-40 \\
-\quad 22 \\
-\quad 4 \\
+\quad 14 \\
+32\end{array}$ & $\begin{array}{r}-40 \\
=\quad 30 \\
=\quad 20 \\
-\quad 10 \\
0\end{array}$ & $\begin{array}{l}335.2 \\
330.5 \\
325.3 \\
319.7 \\
313.6\end{array}$ & $\begin{array}{l}332 \\
324 \\
316 \\
308 \\
300\end{array}$ & $\begin{array}{l}322.0 \\
316.0 \\
309.9 \\
303.8 \\
297.6\end{array}$ & $\begin{array}{l}333.0 \\
329.9 \\
325.8 \\
320.8 \\
314.9\end{array}$ & $\begin{array}{l}332.7 \\
330.6 \\
327.2 \\
322.3 \\
316.1\end{array}$ & $\begin{array}{c}\cdots \ldots \ldots \ldots \\
309.7 \\
\cdots \cdots \cdots\end{array}$ & $\begin{array}{l}33 . . . \\
317.0 \\
309.0 \\
300.4\end{array}$ \\
\hline $\begin{array}{l}+50 \\
+68 \\
+\quad 86 \\
+104 \\
+122\end{array}$ & $\begin{array}{l}+10 \\
+20 \\
+30 \\
+40 \\
+50\end{array}$ & $\begin{array}{l}307.2 \\
300.3 \\
293.0 \\
285.3 \\
\ldots \ldots . . .\end{array}$ & $\begin{array}{l}292 \\
284 \\
276 \\
\ldots \ldots \ldots\end{array}$ & $\begin{array}{l}291.3 \\
284.8 \\
278.4 \\
271.9 \\
265.3\end{array}$ & $\begin{array}{l}308.0 \\
300.1 \\
291.3 \\
281.6\end{array}$ & $\begin{array}{l}308.6 \\
299.9 \\
289.7 \\
278.0\end{array}$ & $\begin{array}{l}298.4 \\
285.4 \\
272.2 \\
258.3 \\
243.6\end{array}$ & $\begin{array}{l}290.9 \\
280.6 \\
269.4 \\
257.4 \\
244.6\end{array}$ \\
\hline $\begin{array}{l}+140 \\
+200 \\
+250 \\
+270\end{array}$ & $\begin{array}{l}+60 \\
+93.3 \\
+121.1 \\
+132.2\end{array}$ & & & 258.6 & . & 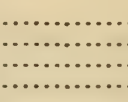 & $\begin{array}{l}227.9 \\
165.2 \\
\end{array}$ & \\
\hline \multicolumn{2}{|c|}{ Temperature } & \multirow{2}{*}{$\underset{1911}{\text { Hybl, }}$} & \multirow{2}{*}{$\begin{array}{c}\text { Macintire, } \\
1911\end{array}$} & \multirow{2}{*}{$\begin{array}{c}\text { Lucke, } \\
1912\end{array}$} & \multirow{2}{*}{$\begin{array}{c}\text { Mosher, } \\
1913\end{array}$} & \multirow{2}{*}{$\begin{array}{c}\text { Holst, } \\
1915\end{array}$} & \multirow{2}{*}{$\begin{array}{c}\text { Keyes, } \\
1916\end{array}$} & \multirow{2}{*}{$\begin{array}{c}\text { Osborne } \\
\text { and } \\
\text { Van Dusen, } \\
1917\end{array}$} \\
\hline${ }^{\circ} \mathrm{F}$ & ${ }^{\circ} \mathrm{C}$ & & & & & & & \\
\hline $\begin{array}{l}-40 \\
=22 \\
\overline{+} 4 \\
+\quad 14 \\
+32\end{array}$ & $\begin{array}{r}-40 \\
=30 \\
=\quad 20 \\
-\quad 10 \\
0\end{array}$ & $\begin{array}{l}325.2 \\
318.2 \\
310.7 \\
302.6\end{array}$ & $\begin{array}{l}327.9 \\
320.8 \\
313.0 \\
304.4\end{array}$ & $\begin{array}{l}335.3 \\
323.1 \\
320.9 \\
313.1 \\
304.6\end{array}$ & $\begin{array}{l}334.4 \\
327.1 \\
319.6 \\
311.8 \\
303.6\end{array}$ & $\begin{array}{l}328.5 \\
322.5 \\
316.0 \\
309.0 \\
301.4\end{array}$ & $\begin{array}{l}342.0 \\
333.6 \\
324.9 \\
315.7 \\
306.0\end{array}$ & $\begin{array}{l}331.7 \\
324.8 \\
317.6 \\
309.9 \\
301.8\end{array}$ \\
\hline $\begin{array}{l}+50 \\
+68 \\
+\quad 86 \\
+104 \\
+122\end{array}$ & $\begin{array}{l}+10 \\
+20 \\
+30 \\
+40 \\
+50\end{array}$ & $\begin{array}{l}293.7 \\
284.2 \\
274.0 \\
263.0\end{array}$ & $\begin{array}{r}295.0 \\
284.7 \\
273.5 \\
\ldots \ldots \ldots\end{array}$ & $\begin{array}{l}294.8 \\
284.6 \\
273.5 \\
261.4 \\
248.3\end{array}$ & $\begin{array}{l}295.0 \\
285.9 \\
276.4 \\
266.2 \\
255.4\end{array}$ & $\begin{array}{l}293.2 \\
284.4 \\
274.8 \\
264.2\end{array}$ & $\begin{array}{l}296.0 \\
285.5 \\
274.4 \\
262.7 \\
250.2\end{array}$ & $\begin{array}{l}293.1 \\
283.8 \\
273.9 \\
263.1 \\
251.4\end{array}$ \\
\hline $\begin{array}{l}+140 \\
+200 \\
+250 \\
+270\end{array}$ & $\begin{array}{l}+60 \\
+93.3 \\
+121.1 \\
+132.2\end{array}$ & & & $\begin{array}{l}234.7 \\
176.7 \\
\ldots \ldots . . .\end{array}$ & $\begin{array}{r}243.7 \\
195.3 \\
127.6 \\
61.2\end{array}$ & (n...... & $\begin{array}{l}235.8 \\
181.9\end{array}$ & \\
\hline
\end{tabular}

\section{REFERENCES}

LEDoux: Annales des Mines, Memoires 7 th series, 14, p. 205; 1878. (Translation by

Denton, Jacobus, and Riesenberger, under title of "Ice Making Machines."

D. Van Nostrand Co. (1892), p. 173.)

MOLLIER: Zeit. ges. Kälte Ind., 2, p. 91 ; 1895.

Wood: Thermodynamics, Heat Motors, and Refrigerating Machines, Ed. 1900, p. 466.

ZEUNER: Technische Thermodynamik, 2, p. I8; rgor (appendix).

DIETERICI: Zeit. ges. Kälte Ind., 11, p. 24; I904.

WobsA: Zeit. ges. Kälte Ind., 15, p. II; I908.

PEABODy: Steam and Entropy Tables (Igog), p. 72.

MACINTIRE: Ice and Refrigeration, 41, p. 44; IgII.

HyвL: Zeit. ges. Kälte Ind., 18, p. r65; I9Ir.

LuckE: Engincering Thermodynamics (I912), p. 603.

MARKs: A. S. R. E. Trans., 8, p. 208; I912.

GOODENOUGH and MOSHER: Univ. of Ill. Bull. 66; I9I3.

Holst: Bull. Assoc. Int. du Froid, 51; r915.

KEYes and BrownleE: Thermodynamic Properties of Ammonia (Igr6). 